\title{
Role of gas molecules in the mitochondrial transport of erythroid- specific 5-aminolevulinate synthase (ALAS2)
}

\author{
By
}

Ahmed M. H. Al-Ansari

\author{
A thesis submitted to \\ the Faculty of Graduate Studies and Research \\ in partial fulfillment of \\ the requirements for the degree of
}

Masters of Science

Biology Department

Ottawa-Carleton Institute of Biology

Carleton University

Ottawa, Ontario

November, 2006

(C) Copyright

2006 Ahmed Al-Ansari 


$\begin{array}{ll}\begin{array}{l}\text { Library and } \\ \text { Archives Canada }\end{array} & \begin{array}{l}\text { Bibliothèque et } \\ \text { Archives Canada }\end{array} \\ \begin{array}{l}\text { Published Heritage } \\ \text { Branch }\end{array} & \begin{array}{l}\text { Direction du } \\ \text { Patrimoine de l'édition }\end{array} \\ \begin{array}{l}\text { 395 Wellington Street } \\ \text { Ottawa ON K1A ON4 }\end{array} & \begin{array}{l}\text { 395, rue Wellington } \\ \text { Ottawa ON K1A ON4 } \\ \text { Canada }\end{array}\end{array}$

Your file Votre référence ISBN: 978-0-494-23358-0 Our file Notre référence ISBN: 978-0-494-23358-0

NOTICE:

The author has granted a nonexclusive license allowing Library and Archives Canada to reproduce, publish, archive, preserve, conserve, communicate to the public by telecommunication or on the Internet, loan, distribute and sell theses worldwide, for commercial or noncommercial purposes, in microform, paper, electronic and/or any other formats.

The author retains copyright ownership and moral rights in this thesis. Neither the thesis nor substantial extracts from it may be printed or otherwise reproduced without the author's permission.
AVIS:

L'auteur a accordé une licence non exclusive permettant à la Bibliothèque et Archives Canada de reproduire, publier, archiver, sauvegarder, conserver, transmettre au public par télécommunication ou par l'Internet, prêter, distribuer et vendre des thèses partout dans le monde, à des fins commerciales ou autres, sur support microforme, papier, électronique et/ou autres formats.

L'auteur conserve la propriété du droit d'auteur et des droits moraux qui protège cette thèse. $\mathrm{Ni}$ la thèse ni des extraits substantiels de celle-ci ne doivent être imprimés ou autrement reproduits sans son autorisation.
In compliance with the Canadian

Privacy Act some supporting forms may have been removed from this thesis.

While these forms may be included in the document page count, their removal does not represent any loss of content from the thesis.
Conformément à la loi canadienne sur la protection de la vie privée, quelques formulaires secondaires ont été enlevés de cette thèse.

Bien que ces formulaires aient inclus dans la pagination, il n'y aura aucun contenu manquant.

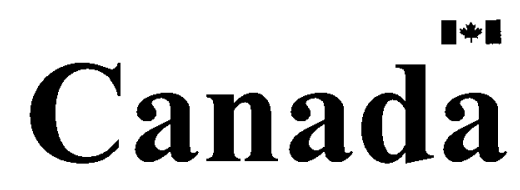




\section{ABSTRACT}

5-Aminolevulinic synthase (ALAS, E.C. 2.3.1.37) is the rate limiting enzyme in the heme biosynthetic pathway. ALAS can only be functional within the mitochondria where it catalyzes the condensation of succinyl $\mathrm{CoA}$ and glycine to give aminolevulinate. Two isoforms of ALAS have been recognized; a nonerythroid-specific isoform (ALAS1) which synthesizes heme for other non-hemoglobin proteins and an erythroid-specific isoform (ALAS2) which synthesizes heme for hemoglobin. In this study we investigated the role of certain gas molecules, namely oxygen $\left(\mathrm{O}_{2}\right)$, nitric oxide $(\mathrm{NO})$, peroxynitrite $\left(\mathrm{ONOO}^{-}\right)$and carbon monoxide $(\mathrm{CO})$, on ALAS2 expression and transport into the mitochondria under normoxic $\left(21 \% \mathrm{O}_{2}\right)$ and hypoxic $\left(1 \% \mathrm{O}_{2}\right)$ conditions. Transiently transfected 293 cells with doubly FLAG-tagged premature ALAS2 were treated with 50 $\mu \mathrm{M}$ SNP and $100 \mu \mathrm{M}$ of $\mathrm{SIN}-1$, the chemical generators of $\mathrm{NO} \cdot$ and $\mathrm{ONOO}^{-}$ respectively. Cells were also treated with gas mixtures containing $10 \%$ and $32 \%$ of CO. Our data demonstrated that ALAS2 expression and mitochondrial import was significantly inhibited by SNP, SIN-1, CO and hypoxia treatments compared to normoxia. Inhibition by SNP, SIN-1 and CO was additive to inhibition by hypoxia. Mitochondrial isolation of transiently transfected 293 cells confirmed the mitochondrial import and processing of ALAS2 and further showed the influence of hypoxia alone or its additive effect with either SNP or SIN-1. Our data suggests that the ALAS2 feedback mechanism cannot be regulated by the binding of heme to the leader sequence of ALAS2. 


\section{ACKNOWLEDGEMENTS}

I am thankful to all my colleagues who helped me by any means during my thesis project. I am also very grateful to my supervisor, Dr. William Willmore, who guided me to discover his interesting area of research where I gained a lot of knowledge and useful experience that will benefit me in my future academic career. I greatly appreciate the opportunity that he provided me to work with him in his laboratory. I would like also to express my pleasure having Drs. Thomas Moon and Shelley Hepworth on my thesis advisory committee as well as Drs. Michel Dumontier and Susan Aitken for being on my thesis defense committee. Sincere thanks is also due to King Abdulaziz University for funding my scholarship.

My extended family members back home also deserve appreciation for all of the support and advice that they have provided me with. I would like to thank all my brothers and sisters who were always very proud of me. I would like also to thank my uncle, Dr. Faisal, who assisted and encouraged me to do my postgraduate studies in Canada. I will also not forget my father-in-law who was calling me by phone regularly and asking about my academic standing; unfortunately he passed away before I completed my Masters degree. Others whom I should recognize are my wife Amrah and my son Mohammed who inspired me and stood beside me throughout my degree particularly at times of discouragement. They were always there whenever I needed them.

I am very happy to be completing my Masters degree and moving on to my Doctoral degree. Finally, I would like to thank my parents who always loved to see me succeed and always stood behind me. Thank you father and mother. 


\section{TABLE OF CONTENTS}

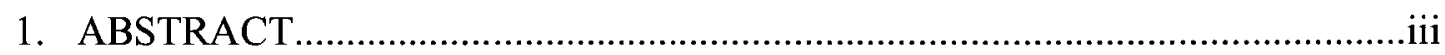

2. ACKNOWLEDGEMENTS................................................ iv

3. TABLE OF CONTENTS ...............................................................................

4. LIST OF FIGURES AND TABLES ......................................viii

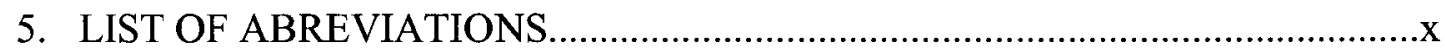

6. INTRODUCTION

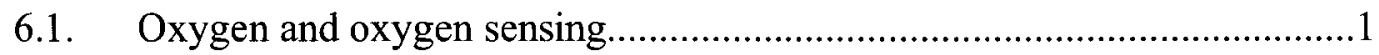

6.2. Aminolevulinic synthase (ALAS) .........................................................

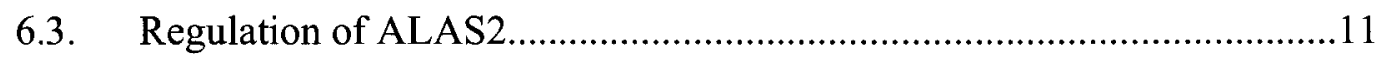

6.4. Mitochondrial protein import.................................................................. 18

6.5. The Tom complex of proteins................................................................19

6.6. The Tim complex of proteins................................................................20

6.7. Mitochondrial Processing Peptidase (MPP) ………………………............23

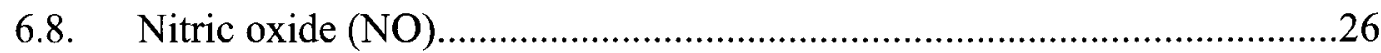

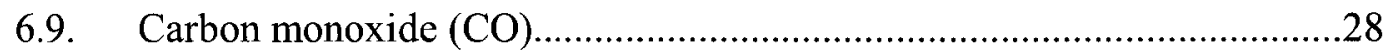

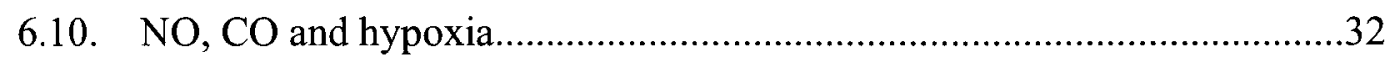

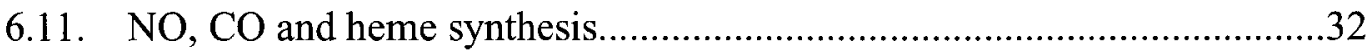

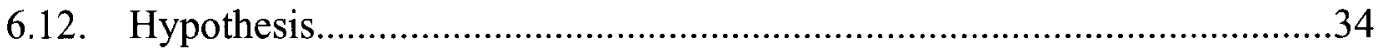

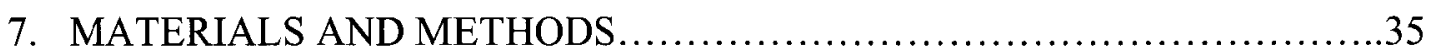

7.1. Chemicals, cell culture and gases....................................... 35

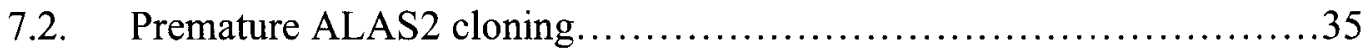


7.3. Site-directed mutagenesis................................... 37

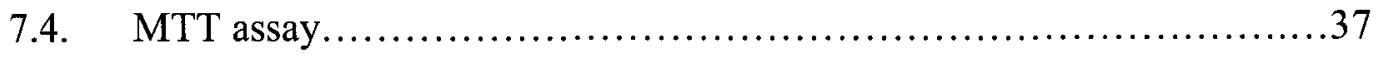

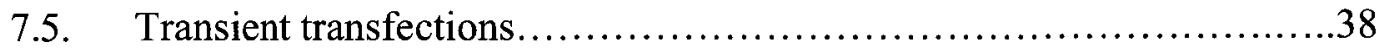

7.6. Western blot............................................... 39

7.7. Western blot stripping......................................40

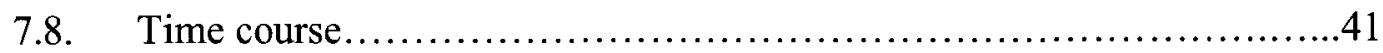

7.9. DNA optimization.......................................... 41

7.10. Mitochondrial isolation...................................... 42

7.11. Assessment of mitochondrial purity.............................43

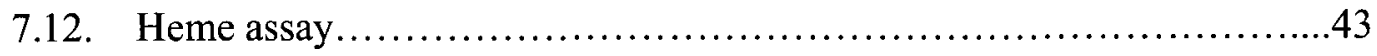

7.13. Hypoxia and hypoxic mimetics............................. 44

7.14. Nitric oxide treatments......................................44

7.15. Carbon monoxide treatments....................................44

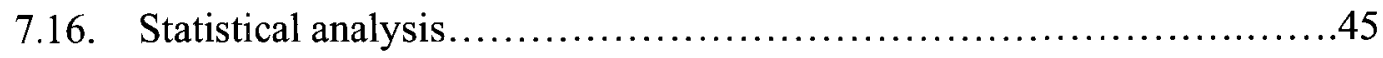

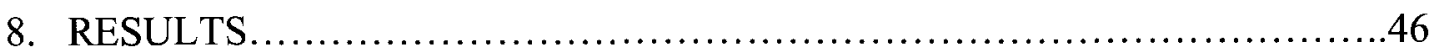

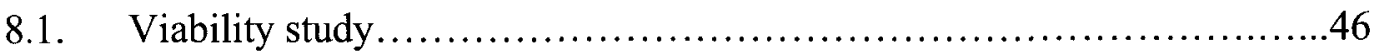

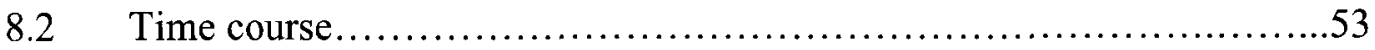

8.3 Optimization of DNA concentration for transfection into 293 cells........53

8.4. Heme and ALAS2 mitochondrial import..........................56

8.5. Hypoxia and hypoxic mimetic treatments..........................61

8.6. Nitric oxide treatments.......................................64

8.7. Mitochondrial isolation.....................................64

8.8 Carbon monoxide treatments....................................69 


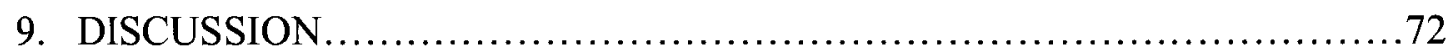

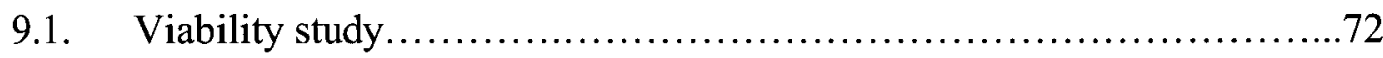

9.2. Time course of ALAS2 expression and mitochondrial import...........73

9.3. DNA concentration and ALAS2 expression and mitochondrial import...74

9.4. Heme association with premature ALAS2 ........................ 75

9.5. Hypoxia, hypoxic mimics and mitochondrial import...................77

9.6. NO and ALAS2 expression and mitochondrial import...................78

9.7. Mitochondrial isolation and ALAS2 import...........................79

9.8. CO and ALAS2 expression and mitochondrial import.................80

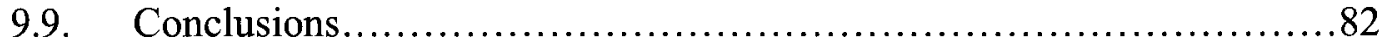

9.10. Further directions.............................................. 82

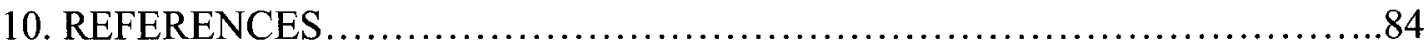




\section{LIST OF FIGURES AND TABLES}

Figure 1: The structure of the hypoxic-inducible factor (HIF) $\ldots \ldots \ldots \ldots \ldots \ldots \ldots \ldots \ldots . .4$

Figure 2: Regulation of hypoxia-inducible gene expression by stabilized HIF-1

under high and low oxygen conditions......................................6

Figure 3: The heme biosynthetic pathway in mammals..........................

Figure 4: Human ALAS2 gene promoter and intron/exon structure................ 12

Figure 5: Solution nuclear magnetic resonance (NMR) structure of the leader

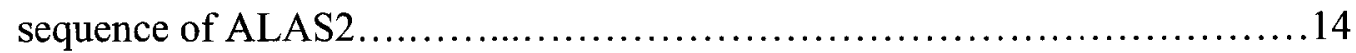

Figure 6: Regulation of ALAS2 expression in erythroid cells in response to Epo........16

Figure 7: Model of preprotein translocation across the mitochondrial membranes......21

Figure 8: Structural elements in the leader sequences required for recognition by

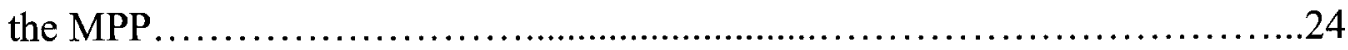

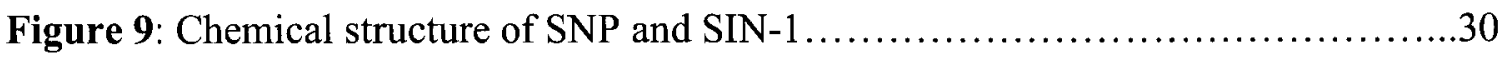

Figure 10: Cell viability of K562 and 293 under increasing amounts of SNP..........47

Figure 11: Cell viability of K562 and 293 under increasing amounts of SIN-1 ........49

Figure 12: Cell viability of 293 under selected concentrations of CO...............51

Figure 13: ALAS2 expression, mitochondrial import and processing after a time course

Figure 14: DNA optimization and ALAS2 expression, mitochondrial import and processing......................................................... 57

Figure 15: Heme and ALAS2 mitochondrial import..........................59

Figure 16: Inhibition of ALAS2 expression, mitochondrial import by hypoxia...........62 
Figure 17: Inhibition of ALAS2 expression, mitochondrial import by SNP and

SIN-1

Figure 18: Mitochondrial isolation of ALAS2 after various treatments.

Figure 19: Inhibition of ALAS2 expression and mitochondrial import

by $\mathrm{CO}$

Table 1: Summary of the biological functions of nitric oxide in various tissues.

Table 2: Summary of the biological functions of nitric oxide synthase

(NOS) isoforms 


\section{LIST OF ABBREVIATIONS}

ALAS1: Aminolevulinic acid synthase 1

ALAS2: Aminolevulinic acid synthase 2

ARNT: Aryl hydrocarbon receptor nuclear translocator

CBP: CREB binding protein

CO: Carbon monoxide

$\mathrm{CoCl}_{2}$ : Cobalt chloride

DFO: Desferrioxamine

DMEM: Dulbecco's Modified Eagle Medium

DMSO: Dimethyl sulfoxide

EDRF: Endothelium-derived relaxing factor

EKLF: Erythroid Krüppel-like factor

Epo: Erythropoietin

EpoR: Erythropoietin receptor

FCS: Fetal calf serum

HIF: Hypoxia-inducible factor

HRM: Heme regulatory motif

HRP: Horse radish peroxidase

Hsp: Heat shock protein

IMDM: Isocove's Modified Dulbecco's Media

IDV: Integrated density value

IMP: Inner membrane peptidase 
IRE: Iron response element

IRP: Iron responsive protein

K562: Human chronic myelogenous leukemia cells

MPP: Mitochondrial processing peptidase

MPREP: Mitochondrial precursor protein

MSF: Mitochondrial stimulation factor

PAS: Period/ARNT/Single-minded

PBS: Phosphate buffered saline

PHD: Prolyl hydroxylase domain

PI: Proteasome inhibitor (Cbz-Leu-Leu-Leu-al)

PMSF: Phenylmethylsulfonyl fluoride

RBC: Red blood cell

ROS: Reactive oxygen species

RT-PCR: Reverse transcriptase-polymerase chain reaction

Tim: Translocase of the inner mitochondrial membrame

Tom: Translocase of the outer mitochondrial membrane

Ub: Ubiquitin

UTR: Untranslated region

VEGF: Vascular endothelial growth factor

XLSA: X-linked sideroblastic anemia 


\section{INTRODUCTION}

\subsection{Oxygen and oxygen sensing}

Oxygen $\left(\mathrm{O}_{2}\right)$ is an essential gas for humans and animals as it acts as the final electron acceptor in the electron transfer chain as well as being the substrate for many enzymes such as cytochrome P450 (Toshinori and Lahiri, 2004). It has been shown that at least 200 characterized enzymes require $\mathrm{O}_{2}$ in the reactions that they catalyze (Bunn and Poyton, 1996). The Earth's atmosphere is composed of $21 \% \mathrm{O}_{2}$. This percentage of $\mathrm{O}_{2}$ is called normoxia. Concentrations of $\mathrm{O}_{2}$ above and below $21 \%$ are termed hyperoxia and hypoxia respectively (Safran and Kaelin, 2003). An absence of $\mathrm{O}_{2}$ is termed anoxia (Safran and Kaelin, 2003).

Humans encounter hypoxia under both physiological and pathological conditions (Bunn and Poyton, 1996). Individuals living at high attitudes are chronically exposed to hypoxia. During development, the human fetus encounters relative hypoxia in utero. Various clinical conditions are associated with acute and chronic hypoxia, including anemia, myocardial infarction and cardiac arrest, diabetic retinopathy, stroke and tumor formation (Huang and Bunn, 2003).

At the cellular level, human adaptation to hypoxia involves alterations in protein and gene expression in an attempt to return the cell to normoxic homeostasis (Semenza, 2003). Hypoxic gene expression attempts to a) increase oxygen transport to tissues and b) switch from aerobic to anaerobic biochemical pathways. Hypoxic-inducible genes that increase oxygen transport to tissues includes erythropoietin (Epo; red blood cell 
maturation), vasoendothelial growth factor (VEGF; angiogenesis or the formation of new blood vessels), inducible nitric oxide synthase (iNOS; production of nitric oxide, a vasodilator), heme oxygenase-1 (HO-1; heme turnover), and transferrin and transferrin receptor (increased iron transport into cells for heme synthesis) (Semenza, 2003). The switch from aerobic to anaerobic metabolism is accompanied by increased gene expression of glucose transporter-1 as well as many of the enzymes of glycolysis (hexokinase-1 and -2, triosephosphate isomerase, phosphoglycerate kinase 1, pyruvate kinase M, phosphofructokinase L, and lactate dehydrogenase A (Semenza, 2003). Hypoxia-inducible gene expression is regulated by oxygen-dependent protein modification.

Oxygen-dependent protein modification may be either specific or non-specific. Nonspecific modification is not dependent upon amino acid sequence and is the result of random attacks of proteins by Reactive Oxygen Species (ROS). ROS are partially reduced oxygen species with free electrons present in the outer orbital of one of the molecular oxygen atoms. These species are highly reactive and they attack and damage all major macromolecules in the cell including lipids, carbohydrates, nucleic acids and proteins (Erecinska and Silver, 2001; Watts et al., 2003). ROS include superoxide, hydrogen peroxide, and the highly reactive hydroxyl radical. Aerobic organisms are exposed to ROS produced as byproducts of normal metabolism, with the mitochondria producing the largest amounts of ROS within the cell (Tsutsui, 2006). Random modifications of amino acid side chains can include hydroxylation, oxidation, peroxidation, or carbonyl formation (Stadtman, 2001). The accumulation of proteins 
damaged by ROS leads to the universal theory as to why all organisms age; the carbonyl content of proteins being commonly used as a measure of the overall age of a protein.

Specific oxygen-dependent modification of protein structure and function is amino acid sequence-specific and is catalyzed by enzymes. A prime example of this is the major transcription factor that controls hypoxia-inducible gene expression; the HypoxiaInducible Factors (HIF) (Hofer et al., 2003). HIF is a heterodimeric transcription factor composed of two subunits, an $\alpha$ and a $\beta$ subunit (Figure 1). The HIFs occur in three isoforms, HIF-1, HIF-2 and HIF-3, which show some tissue specificity. The $\beta$ subunit of the HIFs are constitutively expressed and dimerize with many other cellular proteins. The $\alpha$ subunit of the HIFs are only present in the cell under hypoxic conditions. The $\alpha$ subunit contains two copies of an amino acid sequence, LXXLAP where L represents Leucine, $\mathrm{X}$ is any amino acid, $\mathrm{A}$ is Alanine, and $\mathrm{P}$ is Proline which make HIF-1 $\alpha$ oxygen labile. The prolines of the HIF-1 $\alpha$ sequences are hydroxylated by enzymes known as prolyl hydroxylases under normoxic conditions. Once hydroxylated, HIF-1 $\alpha$ is rapidly ubiquitinated and degraded by the proteasome (within $5 \mathrm{~min}$. of exposing cells to normoxic conditions) (Figure 2). Hypoxia removes one of the substrates of the hydroxylation reaction; namely $\mathrm{O}_{2}$. Nonhydroxylated HIF-1 $\alpha$ is stable, travels to the nucleus, dimerizes with HIF-1 $\beta$, and can bind upstream of hypoxia-inducible genes. Other proteins, that contain the same LXXLAP amino acid sequence as HIF-1 $\alpha$ and are regulated in a similar manner as HIF-1 $\alpha$ include the hyperphosphorylated subunit of RNA polymerase II (Kuznetsova et al., 2003) and erythroid-specific 5-aminolevulinic synthase (ALAS2) (our lab, see below) (Abu-Farha et al., 2005). 
Figure 1: Structure of the $\alpha$ and $\beta$ subunits of Hypoxia-Inducible Factor (HIF) transcription factor. HIF is a heterodimeric protein consists of one of three potential alpha subunits (HIF-1 $\alpha$, HIF-2 $\alpha$ or HIF-3 $\alpha$ ) and three potential beta subunits (HIF-1 $\beta$, HIF-2 $\beta$ or HIF-3 $\beta$ ). Each subunit has a DNA-binding (basic) domain and a dimerization domain composed of helix-loop-helix and PAS (Period/ARNT/Single-minded) domains. While HIF- $\beta$ contains only a C-terminal transactivation domain (CAD), HIF- $\alpha$ contains both an N-terminal (NAD), C-terminal (CAD) transactivation domain as well as the oxygen dependent degradation (ODD) domain, which contains the two LXXLAP amino acid sequences of HIF- $\alpha$ (with permission from Willmore 2004). 


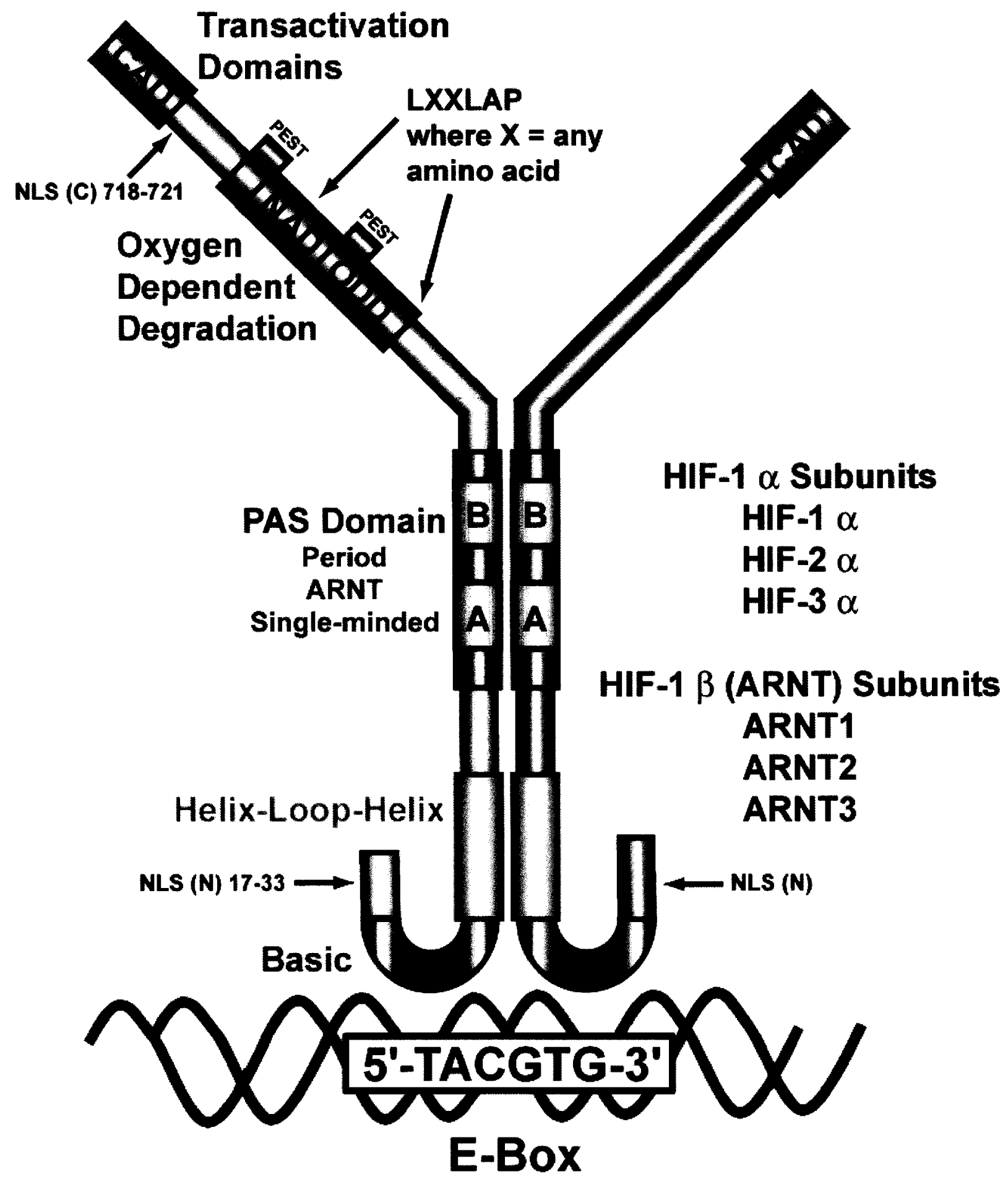


Figure 2: Regulation of hypoxia-inducible gene expression by stabilized of HIF-1 under high and low oxygen conditions. Under normoxic conditions, HIF-1 $\alpha$ is hydroxylated at two prolines, permitting the binding of E3 ubiquitin ligases, ubiquitination of HIF-1 $\alpha$ and subsequent degradation by the proteasome. With the removal of $\mathrm{O}_{2}$ during hypoxic conditions, HIF-1 $\alpha$ is not hydroxylated, not recognized by ubiquitin ligases and is not ubiquitinated nor degraded. Stabilized HIF-1 $\alpha$ can migrate into the nucleus where it binds to its partner protein, HIF-1 $\beta$ (ARNT). Only after dimerization can HIF-1 bind to Hypoxia Response Elements (HREs) present upstream of hypoxia-inducible genes. HIF-1 interacts with the basal transcription machinery through a bridging protein CREB binding protein (CBP) or $\mathrm{p} 300$, via its transactivation domains, to increase the rate of transcription of downstream genes (with permission from Willmore 2004). 


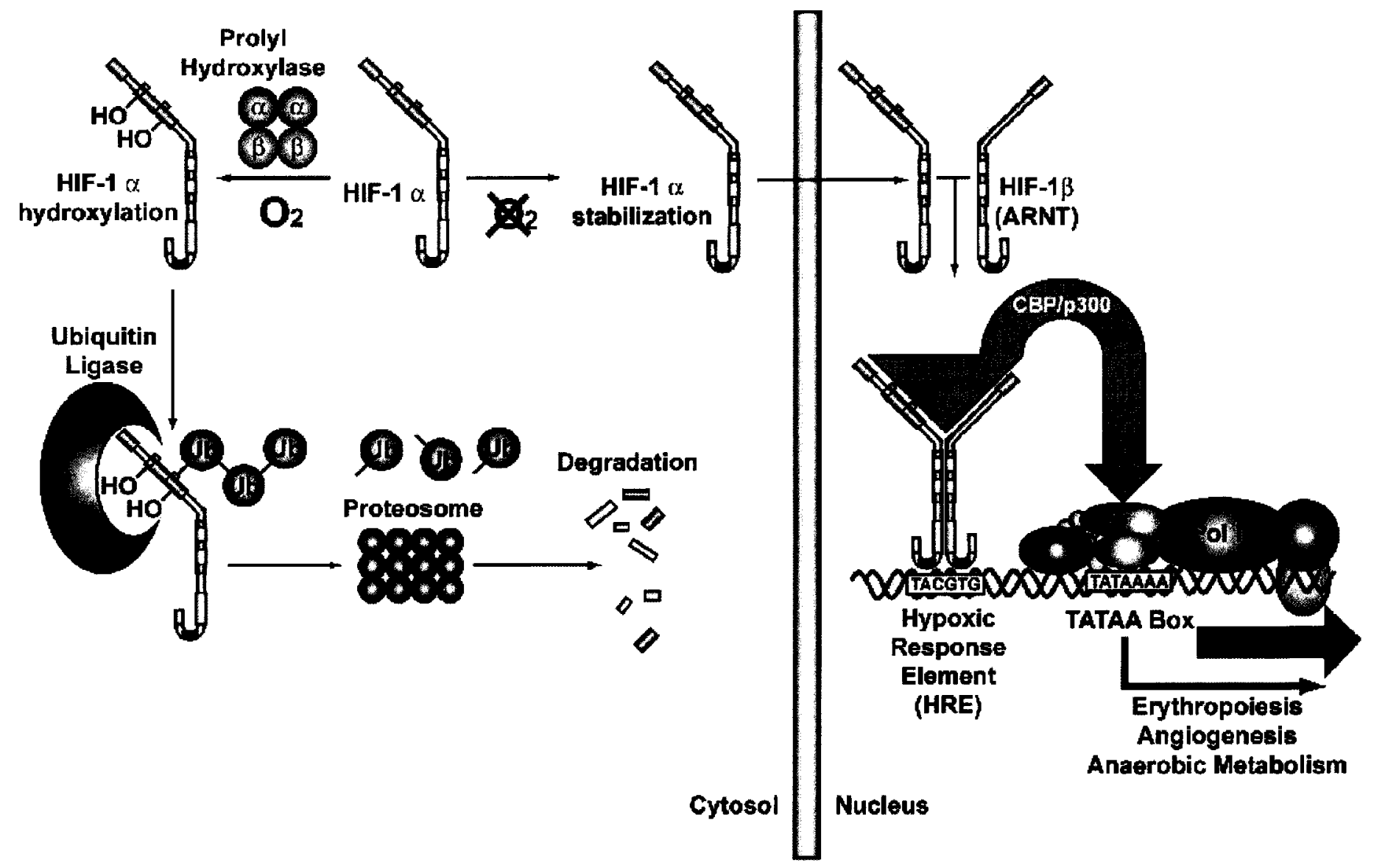




\subsection{Aminolevulinic synthase (ALAS)}

5-Aminolevulinic synthase (ALAS, E.C. 2.3.1.37) is a mitochondrial enzyme that catalyzes the first step of the heme biosynthetic pathway. Within the mitochondria, it catalyzes the condensation of succinyl $\mathrm{CoA}$ and glycine to give aminolevulinate (Figure3). ALAS exists in two known isoforms. The non-erythroid-specific isoform (ALAS1), which is ubiquitous to all tissues, synthesizes heme for non-hemoglobin proteins (cytochromes, enzymes, etc). The erythroid-specific isoform (ALAS2) is expressed exclusively in erythroid cells and synthesizes heme for hemoglobin (AbuFarha et al., 2005; Munakata et al., 2004). Several studies have demonstrated that both ALAS isoforms are highly regulated at several levels, including transcription, translation, and translocation into mitochondria (Sadlon et al., 1999). Like HIF-1 $\alpha$, ALAS2 contains the LXXLAP sequence, which can be potentially hydroxylated by prolyl hydroxylases (Abu-Farha et al., 2005). Our lab has provided evidence that ALAS2 is stabilized by proteasome inhibition and hypoxia $\left(\begin{array}{lll}1 \% & \mathrm{O}_{2}\end{array}\right)$ in the differentiated human erythroid leukemia cell line, K562. We further showed that ALAS2 can be ubiquitinated under normoxic conditions. The stabilization of ALAS2 occurs in conjunction with iron transport into the cell, heme synthesis and erythropoiesis under hypoxic conditions. Other studies have shown that hypoxia $\left(1 \% \mathrm{O}_{2}\right)$ stabilized the same protein in differentiated mouse erythroid leukemia (MEL) cells (Hofer et al., 2003). 
Figure 3: The heme biosynthetic pathway in mammals. The enzymes involved in heme synthesis are compartmentalized between the mitochondria and cytosol, with the first (ALAS) and the last three enzymes being located in the mitochondria. ALAS catalyzes the conversion of succinyl CoA and glycine to aminolevulinate. Two aminolevulinates combine to form porphobilinogen, four of which combine to form the porphorin ring. The final enzyme, ferrochelatase, catalyzes the insertion of iron into protoporphyrin IX to form heme (with permission from Willmore 2004) 


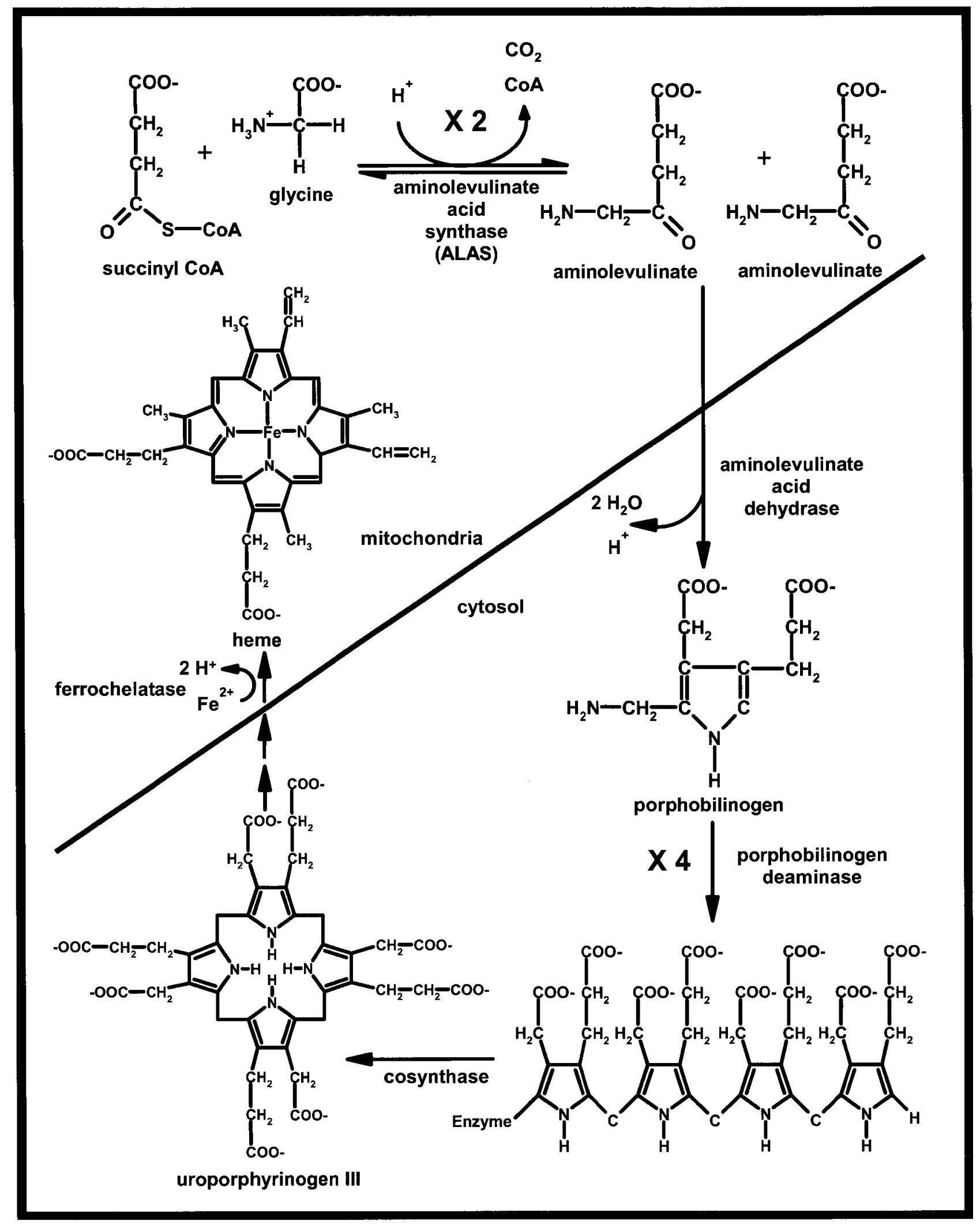




\subsection{Regulation of ALAS2}

The gene for the human premature form of ALAS2 occurs on the X chromosome and is a $22 \mathrm{~Kb}$ gene which consists of 11 exons and 10 introns (Sadlon et al., 1999). The ALAS2 promoter sequence includes binding sites for transcription factors GATA-1 and erythroid Krüppel-like factor (EKLF) (Figure 4 and Figure 5). These transcription factors play a critical role in the erythroid-specific activation and upregulation of the globin genes. Exon 1 contains a sequence encoding for an iron response element (IRE) while exon 2 is believed to contain the mitochondrial localization sequence. The catalytic domain of the enzyme is thought to be contained within exons 5-11. Alternative splicing of the ALAS2 gene can eliminate exon 4 and mutation hotspots linked to X-linked sideroblastic anemia (XLSA) can be found in exons 5-11. Like many mitochondrial proteins, ALAS2 is encoded in nucleus, is translated to a premature protein in the cytosol, imported into the mitochondria and processed to give the mature form (Figure 6). Moreover, premature-ALAS2 is prevented from folding in the cytosol by cytosolic heat shock protein 70 (cHsp70). Once it reaches the mitochondria, ALAS2 is imported into the mitochondrial matrix through the translocase of the outer mitochondrial membrane (Tom) and the translocase of the inner mitochondrial membrane (Tim) complexes of proteins in an energy (ATP) dependent manner. Once in the matrix, ALAS2 is processed by the mitochondrial processing peptidase (MPP), which removes the leader peptide, allowing ALAS2 to fold into its final mature form. Some reports have shown that heme binding to the leader peptide of ALAS2 was found to inhibit mitochondrial import and 
Figure 4: Human ALAS2 gene promoter and intron/exon structure. Promoter control sequences important for expression, notably GATA boxes and a CACCC box likely to bind EKLF, are shown. The GATA site at -27 can bind GATA-1 or TATA box binding protein (TBP). Exons are shown as vertical lines: exon 1 encodes the IRE, exon 2 the mitochondrial signal sequence, exons 3 and 4 are of unknown function and exons 5-11 encode the catalytic domain. Erythroid-specific enhancer sequences are present in introns 1 and 8. An alternatively spliced erythroid mRNA lacks exon 4. Mutations identified in X-linked sideroblastic anemia (XLSA) are located in exons 5-11 and are shown as dotted exons (adapted from Sadlon et al., 1999). 
Figure 5: Solution nuclear magnetic resonance (NMR) structure of the leader sequence of ALAS2. A central alpha helix (green) creates a hydrophobic environment, bringing together a number of leader peptides at their centre while the ends (blue and red) are unstructured. Heme potentially binds to a heme regulatory motif (HRM) found in the centre of these peptides (from Goodfellow et al. 2001). 


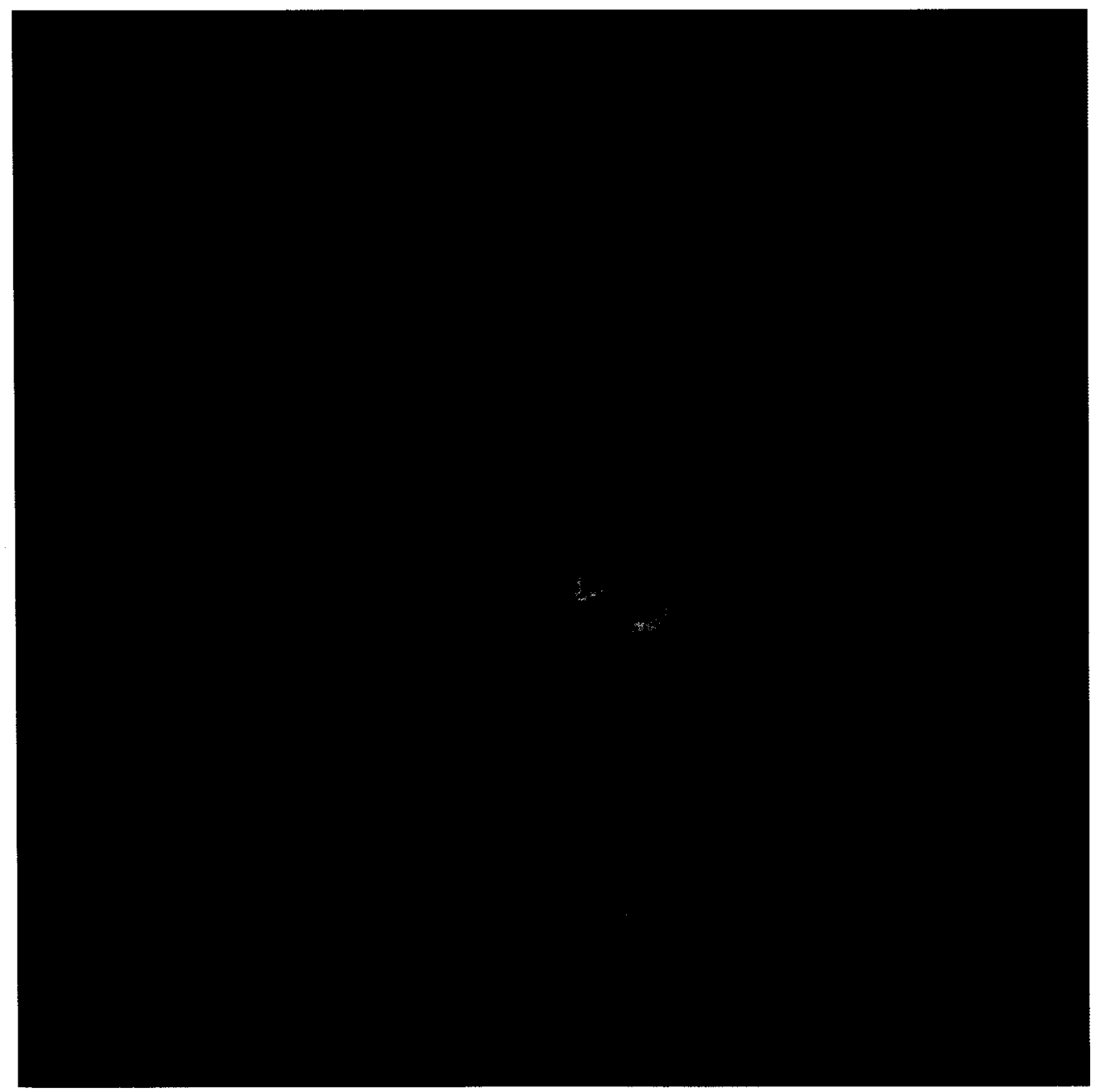


Figure 6: Regulation of ALAS2 expression in erythroid cells in response to Epo. Epo, through the erythropoietin receptor, stimulates transcription of the ALAS2 gene. Translation of ALAS2 mRNA is prevented by the binding of the iron regulatory protein (IRP) but relieved by iron (+), which enters as a complex with transferrin via the transferrin receptor. Following translation, the precursor protein (pre-ALAS2) is imported into mitochondria where it is proteolytically activated. Heme may inhibit translation of ALAS2 mRNA (-) and import of the precursor protein (-) but is necessary for globin mRNA translation (+) (adapted from Sadlon., et al., 1999). 


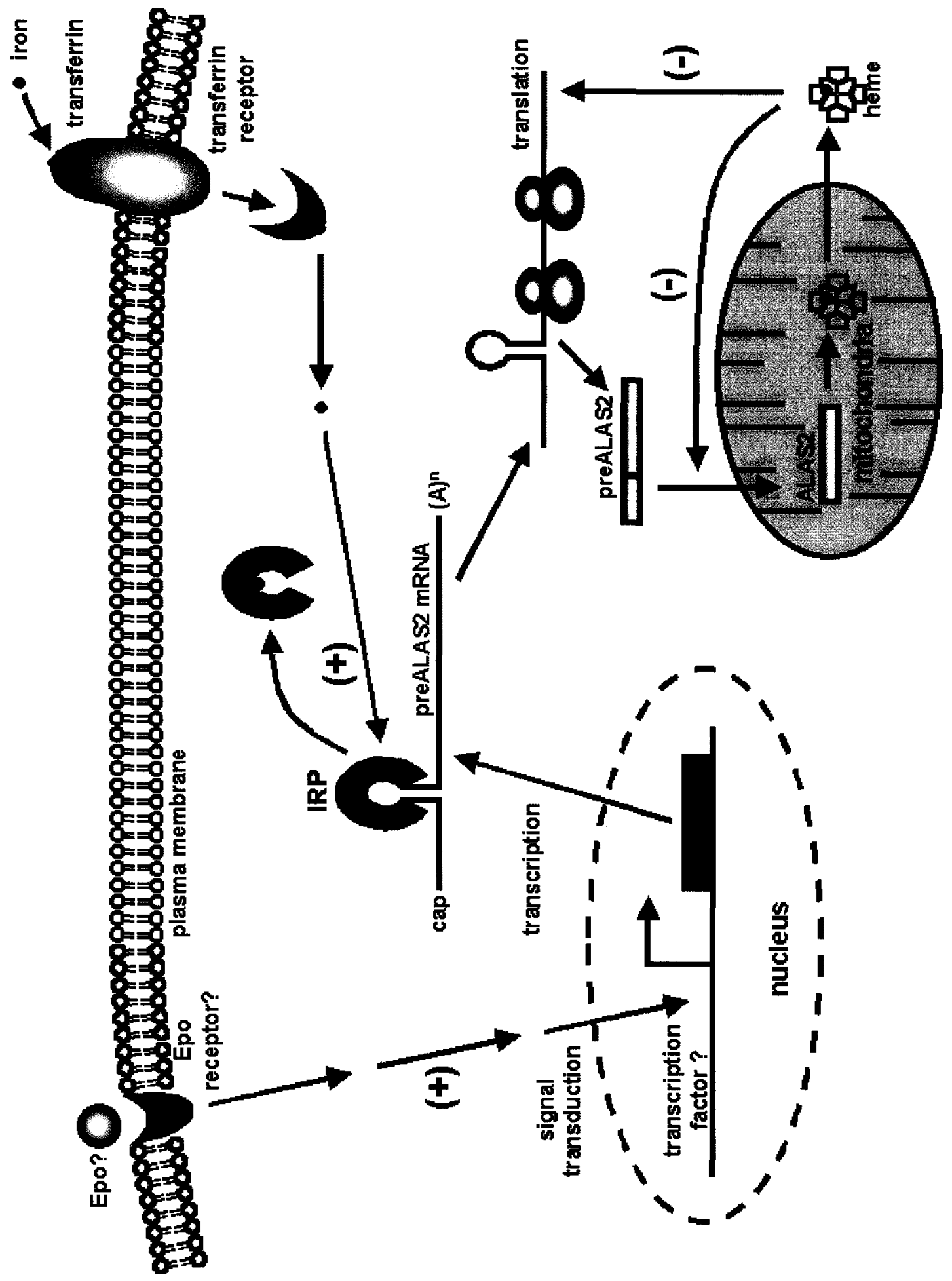


plays a key role in the ALAS2 feedback mechanism (Larthop and Timko, 1993). A specific heme-regulatory motif (HRM), present in the presequence of ALAS2, has been shown to mediate the inhibition of the mitochondrial import of the precursor ALAS2 in the presence of heme (Larthop and Timko, 1993). Two groups have investigated the role of hemin, a commonly used compound in heme-related research, on the import of premature ALAS2 (Dailey et al., 2005; Munakata et al., 2004; Lathrop and Timko, 1993). Hemin is the crystalline chloride form of heme. The iron of hemin has a chloride ion associated with it that partially negates the positive charge of this central ion. Hemin is produced by heating hemoglobin with glacial acetic acid and sodium chloride. Munakata et al. (2004) observed less than 15\% inhibition of rat ALAS2 mitochondrial import by 20-100 $\mu \mathrm{M}$ hemin in the quail fibroblast cell line QT6. In contrast, Lathrop and Timko (1993) have reported that a dose of only $25 \mu \mathrm{M}$ of hemin was sufficient enough to completely inhibit the import of mouse premature ALAS2.

\subsection{Mitochondrial Protein Import}

Almost all mitochondrial proteins are imported into the mitochondria in the same manner, utilizing their N-terminal leader peptide that contains their mitochondrial localization sequence of amino acids. As soon as mitochondrial proteins are transported into the mitochondria, their leader peptides are cleaved off and the rest of the protein folds to form the mature protein (Jensen and Kinnally, 1997; Sadlon et al., 1999). Two complexes of proteins are well known to play an essential role in the import process. 
These complexes have been known as Tom and Tim complexes which facilities the import through the mitochondrial outer and inner membranes respectively (Pfanner and Meijer, 1997; Jensen and Kinnally, 1997; Mori and Terada, 1998). Once within the cell, the MPP cleaves the leader sequence to give the mature protein (Ito, 1999; Braun and Schmitz, 1997). The leader peptide of proteins imported into the mitochondria is positively charged and has an abundance of the basic amino acids. The existence of the positive charge implies a requirement of import machinery that specifically recognizes positively charged molecules.

\subsection{The Tom Complex of Proteins}

The Tom complex acts as a receptor that recognizes, binds, and delivers precursor proteins to the inner membrane (Rehling et al., 2001). It consists of a large number of proteins including Tom5, Tom6, Tom20, Tom22, Tom37, Tom40, Tom70, and Tom72 (Figure 7). The import of precursor proteins depends primarily on their shape and their positively charged presequence. Two types of mitochondrial precursor proteins (MPREP) exist. Type I contains a distinct N-terminal leader sequence. In contrast, Type II contains a semi internal leader sequence. Tom20 and Tom 22 are the two receptor proteins which bind to the first type by their negatively charged residues. Tom70 and Tom37 bind the second type, which is more hydrophobic, by the interaction of the mitochondrial import stimulation factor (MSF) with MPREP that are captured by Tom70 and Tom37 (Pfanner and Meijer, 1997). The $70 \mathrm{kDa}$ cytosolic heat shock protein 70 (cHsp70), which binds

Type I MPREP shortly after (Pfanner and Meijer, 1997) or even during its translation, 
plays a protective role against inaccurate binding (Pfanner and Meijer, 1997) and aggregation (Gakh et al., 2002; Mori and Terada, 1998). It was also found that cHsp70 specifically binds mitochondrial precursor and mature proteins. However, cHsp70 is not capable of binding cytosolic MPREP Type II proteins (Mori and Terada, 1998). Type II MPREP was found to interact with MSF another cytosolic protein consisting of two subunits. Since MPREP induces ATPase activity, MSF is thought to play an ATPdependant chaperone role (Pfanner and Meijer, 1997; Mori and Terada, 1998).

\subsection{The Tim Complex of Proteins}

The Tim complex is a membrane receptor exclusively on the mitochondrial inner membrane receptor of MPREP (Figure 7). Once they pass through the Tom complex channel, MPREP are brought to Tim by an electrostatic potential $(\Delta \Psi)$ (Mori and Terada, 1998). The Tim machinery consists of a multisubunit complex (Tim23, Tim44, Tim17, Tim11). Tim23-Tim44 and Tim23-Tim17 interact with the mitochondrial matrix Hsp70 (mtHsp70) in order to support the translocation process and to ensure that it is done successfully. The Tim complex requires both inner membrane potential $(\Delta \Psi)$ and ATP to pull MPREP through the inner membrane and into the matrix in order to be cleaved by mitochondrial peptidase (Pfanner and Meijer, 1997). 
Figure 7: "Model of preprotein translocation across the mitochondrial membranes. A mitochondrial preprotein synthesized on cytosolic polysomes with a positively charged targeting sequence can bind to cytosolic chaperones (cytosolic heat shock protein 70 (cHsp70) and mitochondrial import stimulation factor (MSF)) and is targeted to receptors of the translocase of the outer mitochondrial membrane (Tom20-Tom22 or Tom70Tom37). The receptor subcomplexes dynamically interact with a general import pore (Tom40). Small Tom proteins (Tom6 and Tom7) modulate the dynamics of the translocase. Preprotein translocation across the inner membrane requires the Tim machinery, with Tim23 and Tim17 as at least part of the channel. The membrane potential $(\Delta \Psi)$ supports dimerization of $\operatorname{Tim} 23$ and is thought to exert an electrophoretic effect on the targeting sequences. Tim23-Tim44 and Tim23-Tim17 subcomplexes transiently interact with matrix Hsp70 (mtHsp70) and the co-chaperone Mge1, and the cycle of association, ATP hydrolysis and dissociation constitutes an ATP-driven import motor. The mitochondrial processing peptidase (MPP) selectively removes aminoterminal targeting sequences. Folding in the matrix can proceed directly or be assisted by various chaperones. A subcomplex containing Tim22 is involved in import of some integral inner membrane proteins without a presequence; it is not known if $\operatorname{Tim} 22$ interacts with the main Tim machinery shown in this diagram" (taken from Pfanner and Meijer, 1997). 


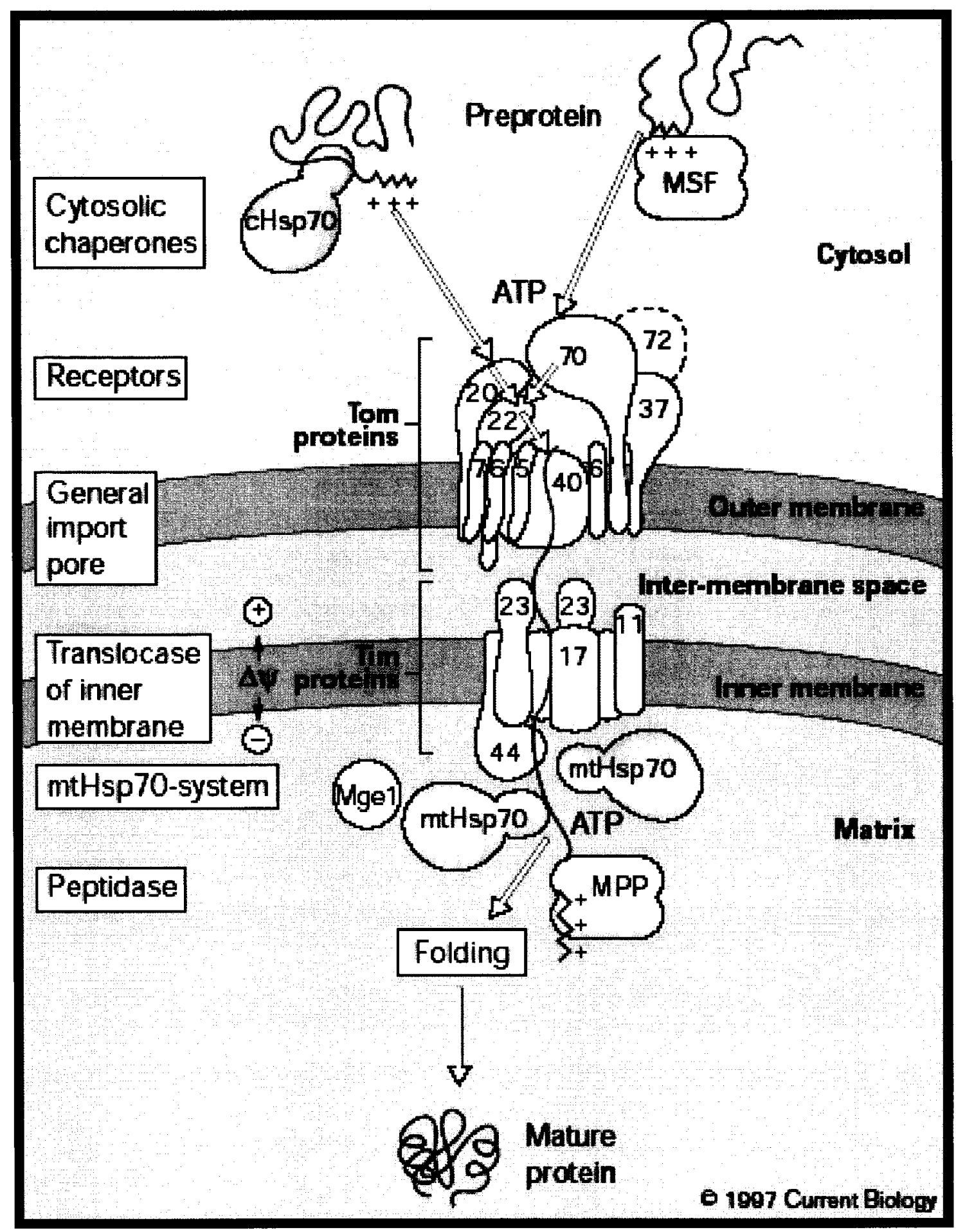




\subsection{Mitochondrial Processing Peptidase (MPP)}

The MPP is a mitochondrial protease, which consists of alpha and beta subunits ( $\alpha$ MPP and $\beta$-MPP). The MPP recognizes large variety $\mathrm{N}$-terminus extension leader peptides of MPREP and generally cleaves it off at a specific site (Figure 8) (Ito, 1999). The existence of arginine residue at the -2 position from the cleavage site is an important feature of the amino acid sequence recognized and cleaved (Gakh et al., 2002). It is possible that the MPP leaves some residues of the leader peptide after processing the precursor proteins. However, this remaining part can be removed by other mitochondrial peptidases (Ito, 1999). Gakh et al., (2002) demonstrated that the MPP has two more assistant proteins encoding for mitochondrial intermediate peptidase (MIP) and inner membrane peptidase (IMP), which take care of removing any leader peptide residues (Gakh et al., 2002). Due to the fact that the MPP is the only protease that processes precursor proteins, it has attracted a lot of research. The molecular properties and structure of the MPP have been well studied in yeast, Neurospora, rat, and the potato (Ito, 1999). Those studies concluded that $\alpha$ and $\beta$ subunits of the MPP are not only highly homologous between the two subunits but are also homologous between organisms (Ito, 1999). Gas molecules such as carbon monoxide (CO) or nitric oxide (NO) may affect MPP function indirectly by affecting cell viability. Maneiro et al. (2005) showed that NO released in human chondrocytes culture by sodium nitroprusside (SNP) at concentrations higher than $0.5 \mathrm{mM}$ for $24 \mathrm{hrs}$ induced cellular apoptosis by inhibiting the mitochondrial respiratory chain; mainly at complex IV (Maneiro et al., 2005). 
Figure 8: Structural elements in the leader sequences required for recognition by the MPP and the amino acid residues of the MPP subunits involved in the recognition and cleavage reaction. The distal basic amino acids are circled and other functional residues or regions are boxed. Hyphens in the amino acid sequences indicate cleavage sites. $\mathbf{M}^{++}$ denotes an active site metal; in most cases zinc (taken from Ito, 1999). 


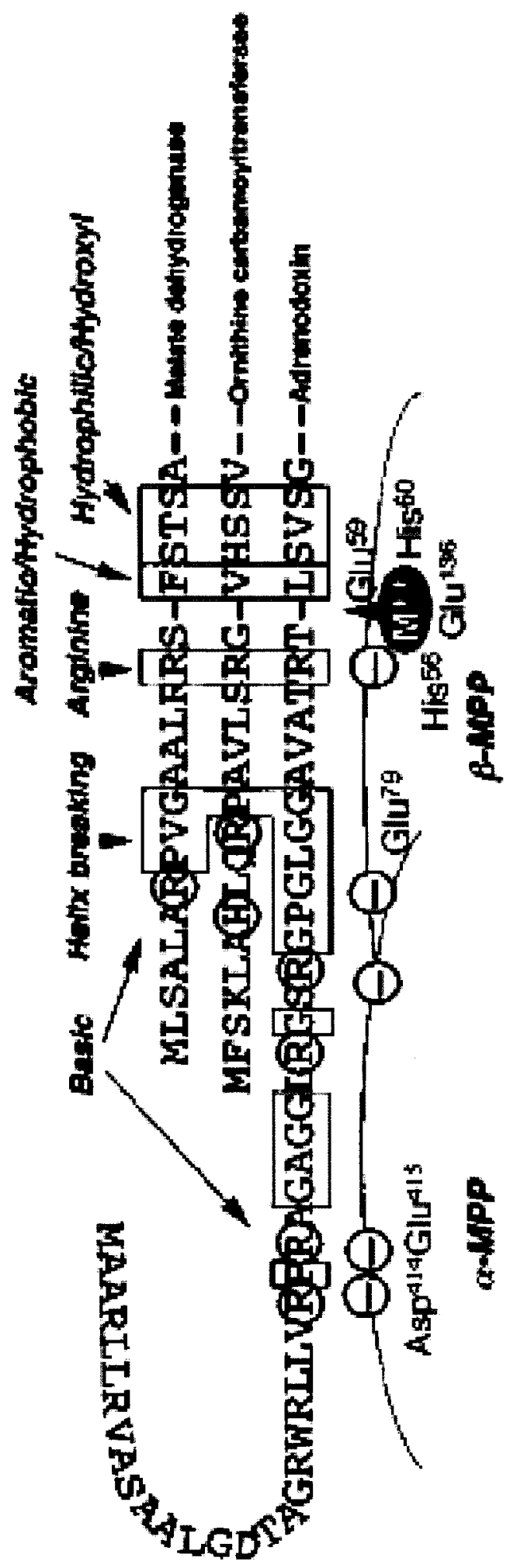




\subsection{Nitric oxide (NO)}

Nitric oxide (NO) is an important gaseous signaling molecule that acts in many tissues to regulate a diverse range of physiological processes such as smooth muscle relaxation, neurotransmission, platelet aggregation, regulation of vascular tone, etc. (Table 1) (Huang and Fishman, 1996), utilizing its ability to diffuse rapidly and easily through cell membranes (Postovit et al., 2004). In 1980 Furchgott and Zawadzki were first to accidentally discover the role of NO as a relaxation factor when they were attempting to identify the agent responsible for promoting blood vessel relaxation and regulating vascular tone. This agent was termed "endothelium-derived relaxing factor" (EDRF), and was initially assumed to be a protein like most other signaling molecules (Furchgott and Zawadzki, 1980). A few years later, it was well agreed among researchers that EDRF is basically NO (Blaise et al., 2005).

NO plays an important role in a wide rang of biological processes such as neurotransmission, immune defense, vascular tone, the control of respiration, the inhibition of platelet aggregation (Watts et al., 2003; Postovit et al., 2004), and the regulation of cell death (apoptosis) (Blaise et al., 2005). Table 1 summarizes some specific tissues in which NO is generated and its function in such tissues (Huang and. Fishman, 1996). Endogenously, NO is generated by nitric oxide synthase (NOS) during the conversion of L- arginine to L-citrulline. Four isoforms of NOS were identified, cloned and characterized in humans as well as other organisms. NOS isoforms were 
Table 1 Summary of the biological functions of nitric oxide in various tissues (reproduced from Huang and Fishman, 1996).

\begin{tabular}{ll}
\hline Biological tissue & Function \\
\hline \hline Central nervous system & Neuronal signaling molecule \\
& Retrograde messenger in long-term potentiation \\
& Mediator of excitatory amino acid neurotransmission \\
& Mediator of excitotoxicity \\
& Coupler of cerebrovascular blood flow to metabolism
\end{tabular}

Peripheral nervous system Neurotransmitter

Smooth muscle relaxation

Vasculature

Vasodilator, regulator of vascular tone

Inhibitor of smooth muscle proliferation

Inhibitor of platelet aggregation

Inhibitor of leukocyte adhesion and activation

Heart

Paracrine modulator of contractility and heart rate

Immune system

Defense mechanism against pathogens

Defense mechanism against tumor cells

Mediator of hemodynamic changes in sepsis 
named according to their existence or function in specific organs; neural NOS (nNOS) or (NOS1), inducible NOS (iNOS) or (NOS2), endothelial NOS (eNOS) or (NOS3), and mitochondrial NOS (mtNOS). The phenotypes of nNOS, eNOS, and iNOS knockout mice are listed in Table 2. Haynes et al. (2004) have identified mtNOS as an alpha isoform of nNOS (Watts et al., 2003; Huang and. Fishman, 1996; Haynes et al., 2004). Experiments with knockout mice confirmed the existence of mtNOS in the mitochondrial inner membrane and also suggest its significant role as a regulatory factor that affects cellular respiration in mitochondria (Acuna-Castroviejo et al., 2005).

NO can be synthesized chemically in vitro or in vivo using a variety of NO generators, including SNP and 3-morpholinosydonimine (SIN-1), a $\mathrm{ONOO}^{-}$donor. The chemical structure of SNP and SIN-1 are shown in Figures 9 A and B respectively. SNP is composed of a central ferrous $(\mathrm{Fe})$ iron surrounded by five cyanide molecules $(\mathrm{CN})$ and a single NO molecule. The ferrous complex is coupled with diatomic sodium (Yamamoto and Bing, 2000). SIN-1 is a double cyclic compound, which functions as a hepatic metabolite. SIN-1 can release NO in various forms such as nitrite and nitrate. SNP has to be reduced by a reducing agent in presence of light in order to be capable of releasing NO (Yamamoto and Bing, 2000).

\subsection{Carbon Monoxide (CO)}

Environmentally, carbon monoxide (CO) is a colorless, odorless, tasteless and 
Table 2 Summary of the biological functions of Nitric Oxide Synthase (NOS) isoforms (reproduced from Huang and Fishman, 1996).

\begin{tabular}{ll}
\hline NOS isoform & Phenotype \\
\hline \hline Neuronal NOS (type I) & Pyloric stenosis, abnormal IJP responses in gastric molecule \\
& Resistance to focal and global cerebral ischemia \\
Increased aggressive behavior \\
Preserved hippocampal long-term potentiation \\
Non-NO mediated compensation in cerebrovascular response \\
to hypercarbia and whisker stimulation, nociception, and MAC \\
for isoflurane anesthesia
\end{tabular}

Inducible NOS (type II) Increased susceptibility to intracellular pathogens

Increased susceptibility to tumors

Resistance to sepsis-induced hypotension

Endothelial NOS (type III) Absence of EDRF activity in aorta

Elevated mean arterial blood pressure

Increased susceptibility to global ischemia

NO-dependent compensation in pial arteriolar response

to acetylchline 
Figure 9: Chemical structure of a) nitric oxide generator Sodium Nitroprusside (SNP) and b) peroxynitrite generator 3-Morpholinosydnonimime (SIN-1).

a)

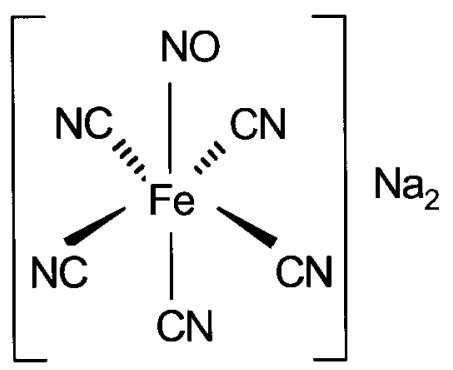

Sodium Nitroprusside (SNP) b)<smiles></smiles>

3-Morpholinosydnonimime (SIN-1) 
poisonous gas. It is the most abundant air pollutant. It is also the most toxic gas humans come into contact with in their daily life (Ryter and Otterbein, 2004). At the cellular level, $\mathrm{CO}$ can be defined as a small membrane-permeable signaling molecule (Watts and Richardson, 2004). Low concentrations of CO, most likely derived from heme degradation by HO enzymes, share some of the same biological activities that NO has, including smooth muscle relaxation, regulation of vascular tone, inhibition of platelet aggregation, and protection against ischemia/reperfusion (I/R) injury (Nakao et al., 2006, Watts et al., 2003 Morita et al., 1997). Endogenous CO is produced by the normal metabolism of cells and organs (Ryter and Otterbein, 2004). The most dominant intracellular source of $\mathrm{CO}$ under normal physiological conditions is the degradation of heme by HO, which exists as a macromolecular complex in the endoplasmic reticulum together with cytochrome c reductase and biliverdin reductase. Heme degradation involves two main reactions. In the first reaction, $\mathrm{HO}$ catalyzes the cleavage of heme ring using heme, three molecules of $\mathrm{O}_{2}$, and NADPH as substrates to produce biliverdin, $\mathrm{CO}$, $\mathrm{Fe}^{2+}$, and $\mathrm{NADP}^{+}$. In the second reaction biliverdin reductase reduces the central methene bridge of biliverdin, producing bilirubin (Watts et al., 2003; Dulak and Jozkowicz, 2003; Maines, 1997). Three isozymes of HO were identified and well characterized namely HO-1, HO-2, and HO-3. The degradation of heme produces up to $86 \%$ of the $\mathrm{CO}$ produced in animal and human cells. The other $14 \%$ of $\mathrm{CO}$ thought to be produced by non-heme processes (Ryter and Tyrrell, 2000). Lipid peroxidation, photo-oxidation, and bacteria are identified to be involved in these processes (Penney, 2000). Exogenously, $\mathrm{CO}$ concentrations are produced in the environment by industrial emissions, vehicle exhausts, cigarette smoke, and other sorts of human activities. 


\subsection{NO, CO and hypoxia}

Both $\mathrm{NO}$ and $\mathrm{CO}$ are thought to have a negative regulatory effect on proteins that are involved in cellular oxygen sensing. Both molecules inhibit the stabilization of both ALAS2 and HIF-1 under hypoxic conditions leading to its degradation. This theory was supported by the findings of several recent studies. Postovit et al. (2004) have found that as low as $1 \mu \mathrm{M}$ of NO derived from NO donors could effectively resist the hypoxic induction of urokinase receptor expression. Another group (Kozhukhar et al., 2006), found that NO prevents the stabilization and accumulation of HIF-1 $\alpha$ in response to hypoxia $\left(1 \% \mathrm{O}_{2}\right)$ in HEK293 cell line. They believe that the generation of $\mathrm{ONOO}^{-}$in the 293 cells leads to damage in the mitochondria leading to the uncontrolled release of superoxide which destabilizes HIF-1 $\alpha$. Huang et al. (1998) have shown that both CO and NO suppressed the activation of HIF-1 $\alpha$ to Epo mRNA. Futhermore, Lin Y et al. (1998) have also shown that $\mathrm{CO}$ and NO have a similar effect on the HIF-1 controlled expression of VEGF.

\subsection{NO, CO and heme synthesis}

Uptake of $\mathrm{NO}$ and $\mathrm{CO}$ from the environment can occur by several means, the most important of which is by inhalation. It has been well known that heme has a high affinity for both gas molecules and that they act as ligands to complete the hexa coordination shell of iron $(\mathrm{Fe})$. The common mechanism by which all hemoglobins bind $\mathrm{O}_{2}, \mathrm{NO}$, and 
CO was proposed (Chan, 2003). Heme iron is attached covalently to the proximal histidine of the globins polypeptide. A second histidine group known as the distal histidine modifies the shape of the polypeptide to form a hydrophobic pocket so that only small molecules can fit and interact with the heme iron (Chan, 2003). The distal histidne enhances the electrostatic interaction between $\mathrm{O}_{2}$ and the heme iron reversibly to form a weak bond so that it can be released easily when required however, the interaction between heme and either CO or NO is irreversible (Chan, 2003). While NO is able to bind both $\mathrm{Fe}^{2+}$ and $\mathrm{Fe}^{3+}$ of the heme molecule, $\mathrm{CO}$ can only bind $\mathrm{Fe}^{2+}$ (Ryter and Otterbien, 2004). In recent studies, NO and CO have been shown to affect the intracellular metabolism of Fe via their ability to bind to this transition metal directly due to their high affinity to bind Fe of hemoproteins (Watts et al., 2003). Hemoglobin (Hb) and myoglobin $(\mathrm{Mb})$ are two heme proteins whose physiological role is principally related to their ability to bind $\mathrm{O}_{2}$ (Ordway and Garry, 2004). Mammalian Hbs are tetrameric $\alpha_{2} \beta_{2}$ proteins that transport $\mathrm{O}_{2}$ through the cardiovascular system. Both $\alpha$ and $\beta$ subunits have sequence and structural homology similar to $\mathrm{Mb}$ including a conserved proximal histidine that binds heme. Mbs are the simplest member of the globin family, being comprised of a single subunit. They are typically found in the muscle tissues of vertebrates where they serve a role in $\mathrm{O}_{2}$ storage and transport during hypoxic or anoxic conditions (Chan, 2003, Ordway and Garry, 2004). Hb and Mb properties were discussed in this study in which they found that such properties were relevant to other heme portions properties. $\mathrm{NO}$ affinity to bind $\mathrm{Hb}$ is 500,000 times stronger than $\mathrm{O}_{2}$. Moreover, its affinity is 1,500 times stronger than CO affinity (Shapiro, 2003; Ryter and Otterbein, 2004; Watts and Richardson, 2004). 
The combination of $\mathrm{NO}$ with $\mathrm{Hb}$ produces nitrosyl hemoglobin ( $\mathrm{HbNO}$ ) where as the combination of $\mathrm{CO}$ with $\mathrm{Hb}$ produces carboxyhemoglobin $(\mathrm{COHb})$ (Patel et al., 2004; Watts et al., 2003). Many of the biological effects of $\mathrm{NO}$ and $\mathrm{CO}$ can be attributed to the fact that both of them avidly bind Fe within the active sites of numerous proteins. The best characterized of these are the $\mathrm{Hb}$ and $\mathrm{Mb}$. The mechanism of their toxicity is through the binding of $\mathrm{Hb}$. NO and $\mathrm{CO}$ compete against $\mathrm{O}_{2}$ to bind the four heme iron centers of hemoglobin to form $\mathrm{HbNO}$ and $\mathrm{COHb}$ respectively (Ryter and Otterbein 2004; Takahashi et al., 1998). $\mathrm{NO}$ and $\mathrm{CO}$ bound to heme have reduced capacity to deliver $\mathrm{O}_{2}$ to vital organs such as heart and brain. This leads to hypoxic and anoxic conditions (Ryter and Otterbein, 2004; Patel et al., 2003).

\subsection{Hypothesis}

Our hypothesis is that gas molecules such as $\mathrm{O}_{2}$, NO, and $\mathrm{CO}$ may affect heme binding to the leader sequence of wildtype premature ALAS2 and hence influence its transport into the mitochondria. Since gas molecules such as NO and CO have extremely high affinity to bind heme molecule we assume that these gases may interfere with heme binding to ALAS2 and disrupt the premature ALAS2 feedback mechanism and increase the import. Also, the overall expression and mitochondrial import of the wildtype premature ALAS2 might be affected by oxygen tension. In this study we compare the mitochondrial import of ALAS2 under normoxic $\left(21 \% \mathrm{O}_{2}\right)$ and hypoxic $\left(1 \% \mathrm{O}_{2}\right)$ conditions. 


\section{MATERIALS AND METHODS}

\subsection{Chemicals, Cell Culture and Gases}

All chemicals were of the highest quality and purchased from Sigma (St. Louis, MO) unless otherwise specified. All gases were purchased from Praxair (Ottawa, ON). Human embryonic kidney cells (293) were obtained as a gift from Dr. Daniel Figeys (Biochemistry, Microbiology and Immunology, University of Ottawa) and maintained in 87\% Dulbecco's Modified Eagle Medium (DMEM) supplemented with 10\% horse serum, 300 Units $/ \mathrm{mL}$ penicillin, $300 \mu \mathrm{g} / \mathrm{mL}$ streptomycin and $0.75 \mathrm{mg} / \mathrm{mL}$ amphotercin B (Invitrogen, Carlsbad, CA). K562 cells were purchased from the American Type Culture Collection (Manassas, VA) and maintained in 87\% Iscove's Modified Dulbecco's Medium (IMDM) media supplemented with 10\% newborn calf serum, $300 \mathrm{Units} / \mathrm{mL}$ penicillin, $300 \mu \mathrm{g} / \mathrm{mL}$ streptomycin and $0.75 \mathrm{mg} / \mathrm{mL}$ amphotercin $\mathrm{B}$ (Invitrogen, Carlsbad, CA). Cultures were maintained at $37^{\circ} \mathrm{C}$ and $5 \% \mathrm{CO}_{2}$ in a humidified tissue culture incubator (Thermo Forma, Marietta, $\mathrm{OH}$ ).

\subsection{Premature ALAS2 Cloning}

In order to express recombinant premature ALAS2 in mammalian cell-lines under different experimental conditions, premature ALAS2 was cloned in a mammalian expression vector. RT-PCR was performed with the Access RT-PCR System (Promega, Madison, WI). Total RNA was extracted from K562 cells using RNeasy kit (Qiagen, 
Missisauga, ON). The oligonucleotides used for RT-PCR were "premature ALAS2 forward" with the FLAG epitope tag (underlined; referred to as FLAG from here on) and a BamHI site (bold):

\section{5'-TTCGGATCCATGGACTACAAGGACGACGATGACAAACAT}

\section{ATGGTGACTGCAGCCATGCTGCTA-3'}

and "premature ALAS2 reverse" with a KpnI site (bold):

\section{5'-GGCGGTACCGGCATAGGTGGTGACATACTGGGG-3'}

FLAG is an eight amino acid epitope tag (Asp-Tyr-Lys-Asp-Asp-Asp-Asp-Lys), the gene of which was linked in frame with the mature ALAS2 gene so that it could be easily detected and purified using anti-FLAG antibodies. One microgram of total RNA was used in each RT-PCR reaction. The integrity of the total RNA was confirmed by total RNA formaldehyde gel electrophoresis.

PCR products were TA cloned into TOPO-pCR2.1 (cloning vector) (Invitrogen, Carlsbad, CA) and digested with BamHI/KpnI. The insert was removed from this vector and ligated into pFLAG-CMV-5 (expression vector) (Sigma, St. Louis MO) using T4 DNA ligase. After transformation and isolation of plasmids, constructs were screened for FLAG using Hpy99I digestion and sequenced for proper insert orientation and full length. Plasmids from selected positive clones were purified using the GenElute kit (Sigma, St. Louis, MO). DNA was sequenced by Macrogen Inc. (Seoul, Korea), confirming the identity of the cloned gene as premature ALAS2 and the proper orientation in pFLAG-CMV-5. Sequences were analyzed using the Basic Local Alignment Search Tool 2.0 (BLAST) algorithms at the National Centre for Biotechnology Information (NCBI) using default settings. 


\subsection{Site-Directed Mutagenesis}

To remove a stop codon (TAG) which occurred 14 nucleotides upstream the $\mathrm{C}$ terminus FLAG of the premature ALAS2, introduced into the sequence by the PCR Taq polymerase, was replaced by alanine (AAG) using site-directed mutagenesis technique. The QuikChange Site-Directed Mutagenesis Kit from Stratagene (La Jolla, CA) was used to accomplish the mutation according to the manufacturer's protocol. Primers utilized for this purpose were designated as follows:

"Forward Premature ALAS2 mutagenesis"

5'-TCTGTGCGGCTGCTCAAGGGAGAGGAGGGCC-3'

and "Reverse Premature ALAS2 mutagenesis"

\section{5'-GGCCCTCCTCTCCCTTGAGCAGCCGCACAGA-3'.}

Post-mutation purified DNA minipreps (Sigma GenElute Plasmid Miniprep Kit) were sent for sequencing to Macrogen Inc. in order to further confirm the removal of the mutation.

\subsection{MTT Assay}

The amount of yellow MTT (3-(4,5-Dimethylthiazol-2-yl)-2,5-diphenyltetrazolium bromide) reduced to purple formazan can be used to assess cell viability after treating with chemicals of interest. The reduction process takes place only when mitochondrial 
reductase enzymes are active in only living cells, and thus conversion is directly related to the number of viable cells. The formazan product is solubilized by lysing cells in $100 \%$ DMSO and then quantified using a simple colorimetric assay (Mosmann 1983) using a spectrophotometric microplate reader (SpectroMax $340^{\mathrm{PC}}$, Molecular Devices, Sunnyvale, CA).

K562 and 293 cells were plated in 96-well plate at a density of $6 \times 10^{5}$ cells/mL and treated with different concentrations of SNP and SIN-1. A stock solution of MTT was prepared at a $5 \mathrm{mg} / \mathrm{mL}$ concentration in PBS, filtered and stored at $4^{\circ} \mathrm{C}$. The volume of MTT added was $10 \%$ of the total volume of media in each well. The plates were incubated at $37^{\circ} \mathrm{C}$ for a full $24 \mathrm{hrs}$. The treated $\mathrm{K} 562$ cells were spun 96-well plates using the microplate benchtop centrifuge for $5 \mathrm{~min}$ at $5000 \mathrm{rpm}$ at $4^{\circ} \mathrm{C}$. The media was very gently taken off and replaced with $10 \%$ of the total volume of DMSO and incubated at room temperature for about 5-10 min. The absorbance was then measured using a SpectraMax $340^{\mathrm{PC}}$ microplate reader at a wavelength of $570 \mathrm{~nm}$ with background subtraction at $630 \mathrm{~nm}$. The experiments were done using six replicates for $\mathrm{K} 562$ and four replicates for 293 cells. The same assay was also used to assess the effect CO on 293 cell viability.

\subsection{Transient Transfections}

In order to examine the expression of recombinant ALAS2 in mammalian cell-line, transient transfections were preformed as described in the protocol for Lipofectamine 
2000 (Invitrogen, Carlsbad, CA) with some changes. All transient transfection were done using 293 cells since this type of cells are non-erythroid cell-lines that lack any endogenous concentrations of ALAS2. In other words, only recombinant ALAS2 would occur in transfected cells. Briefly, 293 cells were washed with $1 \mathrm{X}$ phosphate buffered saline (PBS), trypsinized, counted, and plated at the density of $6 \times 10^{5}$ cells $/ \mathrm{mL}$ one day prior to transient transfections in $500 \mu \mathrm{L}$ of transfection medium (90\% DMEM and $10 \%$ horse serum without antibiotics). All transfections were carried out in 24-well plates unless otherwise specified. On the day of transfection, $0.8-1 \mu \mathrm{g}$ of DNA were gently diluted in $50 \mu \mathrm{L}$ of Opti-MEM I Reduced Serum Medium (Invitrogen, Carlsbad, CA). In a separate tube, $2 \mu \mathrm{L}$ of Lipofectamine 2000 were gently diluted in the same amount of Opti-MEM medium. Both tubes were incubated at room temperature for 5 minutes. After the incubation period, the contents of the tubes were combined and incubated at room temperature for another 20 minutes. Afterwards, the DNA-Lipofectamine 2000 complexes were added directly cells and plates were incubated at $37^{\circ} \mathrm{C}$ in a $\mathrm{CO}_{2}$ incubator for another $24 \mathrm{hrs}$.

\subsection{Western Blot}

After transient transfection, cells were harvested by washing and scraping with $1 \mathrm{X}$ PBS and then they were lysed in whole cell extract lysis buffer (PBS containing 1\% Igepal, $0.5 \%$ sodium deoxycholate, $0.1 \% \mathrm{SDS}$, and $0.01 \%$ protease inhibitor cocktail). The protein content of cell lysates were determined by the Bio-Rad protein assay method 
(Pierce, Rockford, IL). In each lane, $150 \mu \mathrm{g}$ of total protein was boiled in Laemmli sample buffer (Bio-Rad, Hercules, CA), loaded and subjected to electrophoresis in a 10\% sodium dodecyl sulfate polyacrylamide gel (SDS-PAGE). Prestained broad range markers (New England Biolabs, Ipswich, MA) were used as protein standards on SDSPAGE. After electrophoresis, proteins were transferred overnight onto Immobilon-P transfer membrane (Millpore, Billerica, MA) at $180 \mathrm{~mA}$ at $4^{\circ} \mathrm{C}$ according to the procedure of Towbin at el. (1979). The membranes were then blocked with blocking solution $(5 \%(\mathrm{w} / \mathrm{v})$ Carnation nonfat dry milk in TBST buffer $(20 \mathrm{mM}$ Tris- $\mathrm{HCl}, \mathrm{pH} 7.6$, $137 \mathrm{mM} \mathrm{NaCl}$, and $0.1 \%$ Tween 20)), for $1 \mathrm{hr}$ and incubated with monoclonal horseradish peroxidase-conjugated mouse anti-FLAG M2 antibody (1:2000 dilution; Sigma, St. Louis, MO) in blocking solution for $1 \mathrm{hr}$ at room temperature. After 3 washes for 30 minutes in TBST buffer, the membrane was subjected to the Millipore chemiluminescent substrate (Millipore, Billerica, MA) for $1 \mathrm{~min}$ and exposed to film (Kodak XB-1, Kodak, Toronto, ON) for 2 min and then developed.

\subsection{Western Blot Stripping}

Membranes previously exposed to anti-FLAG M2 HRP antibody were washed four times with TBST buffer for $5 \mathrm{~min}$ at room temperature and then were incubated at $50^{\circ} \mathrm{C}$ for $30 \mathrm{~min}$ in stripping buffer containing $62.5 \mathrm{mM}$ Tris, $\mathrm{pH} 6.8,2 \% \mathrm{SDS}$ and $100 \mathrm{mM} \beta$ mercaptoethanol. Subsequently, membranes were washed six times with TBST buffer for $5 \mathrm{~min}$ at room temperature. Finally, membranes were blocked in blocking solution 
overnight with gentle shaking at $4^{\circ} \mathrm{C}$. Following overnight blocking, membranes were incubated with anti tubulin antibody (1:2,000; Developmental Studies Hybridoma Bank, University of Iowa) in blocking solution for $1 \mathrm{hr}$. Membranes were subjected to three washes in TBST buffer for $30 \mathrm{~min}$ each and then incubated with secondary goat antimouse HRP antibody (1:2000; DAKO, Mississauga, ON) for $1 \mathrm{hr}$ at room temperature and washed three times with TBST buffer for 30 min each. Finally, membranes were subjected to the Millipore chemiluminescent substrate and exposed to film as described previously.

\subsection{Time Course}

The optimum time for ALAS2 expression and mitochondrial transport was assessed by conducting a time course of transfection. According to Lipofectamine 2000 (Invitrogen, Carlsbad, CA) transfection protocol, $0.8 \mu \mathrm{g}$ of DNA and $2 \mu \mathrm{L}$ of Lipofectamine per well were transiently transfected in 9 wells of 24 -well plates. Cells were harvested at different time points $0,1,2,4,6,12,24,48,72 \mathrm{hrs}$ as described above and then stored at $-80^{\circ} \mathrm{C}$.

\subsection{DNA Optimization}

The optimal DNA concentration that allows the maximal production of mature ALAS 2 was examined. Cells were transiently transfected for $24 \mathrm{hrs}$ with the following 
concentrations of DNA: 0.0, 0.2, 0.4, 0.6, 0.8, $1.0 \mu \mathrm{g}$ per well. Cells were harvested and assessed as described above.

\subsection{Mitochondrial Isolation}

Mitochondria were isolated from transiently transfected 293 cells by harvesting the cells at $1000 \mathrm{Xg}$ and $4{ }^{\circ} \mathrm{C}$ for $5 \mathrm{~min}$. Cell pellets were then resuspended in $50 \mu \mathrm{L}$ of mito buffer (10 mM Tris $\mathrm{HCl}, \mathrm{pH} 7.8,0.2 \mathrm{mM}$ EDTA, $0.25 \mathrm{mM}$ sucrose). Cells were quickly frozen in liquid nitrogen and thawed on ice in order to weaken the cell walls. Once thawed, $10 \mathrm{mM}$ triethanolamine in $\mathrm{H}_{2} \mathrm{O}$ and $0.1 \mathrm{mg} / \mathrm{mL}$ digitonin in DMSO were added to further weaken the cell wall. Lysed cells were then homogenized in a pre-cooled glassteflon homogenizer using 15 strokes. Homogenized cells were then spun at $1000 \mathrm{X} \mathrm{g} 10$ min at $4^{\circ} \mathrm{C}$. Supernatants were removed and transferred to new Eppendorf tubes. The remaining pellets were resuspended in $50 \mu \mathrm{L}$ of mito buffer supplemented with only 0.1 $\mathrm{mg} / \mathrm{mL}$ digitonin and homogenized as described above. Resuspensions were also spun at $1000 \mathrm{Xg}$ for $10 \mathrm{~min}$ at $4^{\circ} \mathrm{C}$. The supernatants from the two low speed centrifugations were combined and pellets were discarded. The combined supernatant was centrifuged at high speed $12,000 \mathrm{Xg}$ for $15 \mathrm{~min}$ at $4^{\circ} \mathrm{C}$ in order to isolate the mitochondria. The supernatant from this high speed centrifugation was discarded and pellets containing mitochondria were resuspended in $50 \mu \mathrm{L}$ of mito buffer supplemented with a very small amount of PMSF. Aliquots of isolated mitochondria were stored at $-80^{\circ} \mathrm{C}$ until use. 


\subsection{Assessment of Mitochondrial Purity}

The purity of isolated mitochondria was assessed by a multiplex PCR amplification of mtDNA (222 bp) and cytosolic $\beta$-globin $(83 \mathrm{bp})$ genomic fragments mtDNA primers:

14619 FOR, 5'-CCCCACAAACCCCATTACTAAACCCA-3'

14841 REV, 5’'TTTCATCATGCGGAGATGTTGGATGG-3'

$\beta$-globin primers:

48550 FOR, 5'-CGAGTAAGAGACCATTGTGGCAG-3'

48634 REV, 5'-GCTGTTCTGTCAATAAATTTCCTTC-3'

according to Godley at el. 2005.

\subsection{Heme Assay}

Heme may bind to the leader sequence of premature ALAS2 and affect its mitochondrial transport. This concept was examined by treating transiently transfected 293 cells with various concentrations of hemin (heme with a chloride ion associated with the iron) $0,5,10,15,25,35,45,55 \mu \mathrm{M}$ for $24 \mathrm{hrs}$. 


\subsection{Hypoxia and Hypoxic Mimetics}

To assess the effect of hypoxia and hypoxic mimetics on the expression and mitochondrial import of recombinant ALAS2, 239 cells were transiently transfected as described above and treated for $24 \mathrm{hrs}$ with normoxia $\left(21 \% \mathrm{O}_{2}\right)$ versus hypoxia $\left(1 \% \mathrm{O}_{2}\right)$ and hypoxic mimetics. Proteosome inhibitor (PI), cobalt chloride $\left(\mathrm{CoCl}_{2}\right)$ and desferrioxamine (DFO) were added to separate cell treatments at a final concentration of $100 \mu \mathrm{M}$ each. This experiment was preformed three times.

\subsection{Nitric Oxide Treatments}

239 cells were transiently transfected as described above and treated for 24 hrs with normoxia $\left(21 \% \mathrm{O}_{2}\right)$ versus chemically produced NO (SNP) and $\mathrm{ONOO}^{-}(\mathrm{SIN}-1)$ at final concentrations of 50 and $100 \mu \mathrm{M}$ respectively in order to evaluate the effect of NO, $\mathrm{ONOO}^{-}$, and $\mathrm{CO}$ (Section 7.15.) on the expression and import of the recombinant ALAS2. This experiment was preformed three times.

\subsection{Carbon Monoxide Treatments}

CO treatment of transiently transfected 293 cells was accomplished using $25 \mathrm{~cm}^{2}$ Corning cell culture flask (Fisher Scientific) fitted with autoclaved rubber stoppers 
punctured with sterile inflow and outflow needles. Gas flow was maintained at 300 $\mathrm{mL} / \mathrm{min}$ or $200 \mathrm{~mL} / \mathrm{min}$ only for hypoxic treatment with high concentrations of $\mathrm{CO}$ using an Environics Series 2000 multicomponent gas mixer (Tolland, CT). Cells were subjected to four gas mixtures: a) normoxia with low $\mathrm{CO}\left(21 \% \mathrm{O}_{2}, 10 \% \mathrm{CO}, 5 \% \mathrm{CO}_{2}\right.$, and balance $\left.\mathrm{N}_{2}\right)$, b) normoxia with high $\mathrm{CO}\left(21 \% \mathrm{O}_{2}, 32 \% \mathrm{CO}, 5 \% \mathrm{CO}_{2}\right.$, and balance $\left.\mathrm{N}_{2}\right)$, c) hypoxia with low $\mathrm{CO}\left(1 \% \mathrm{O}_{2}, 10\right.$ or $80 \% \mathrm{CO}, 5 \% \mathrm{CO}_{2}$, and balance $\left.\mathrm{N}_{2}\right)$ and d) hypoxia with high $\mathrm{CO}\left(1 \% \mathrm{O}_{2}, 32 \% \mathrm{CO}, 5 \% \mathrm{CO}_{2}\right.$, and balance $\left.\mathrm{N}_{2}\right)$.

\subsection{Statistical Analysis}

IDV values were determined from scanned films using the AlphaEaseFC image analysis software (Alpha Innotech Corporation, San Leandro, CA) Data were expressed as Mean \pm Standard Error of the Mean. Comparisons between treatments and within groups were performed using one-way and two-way ANOVAs followed by Tukey test using Origin 7.0 software (OriginLab Corporation, Northampton, USA) Statistical significance was represented by $\mathrm{P}$ values of $\mathrm{p}<0.05\left(^{*}\right), \mathrm{p}<0.01\left({ }^{* *}\right)$ and $\mathrm{p}<0.001$ $(* * *)$. 


\section{Results}

\subsection{Viability Study}

In order to chemically produce the highest possible concentrations of $\mathrm{NO}$ or $\mathrm{ONOO}^{-}$, without affecting cell viability, we examined the viability of both K562 cells and 293 cells treated with different concentrations of SNP or SIN-1 for 24 hrs using the MTT assay. In this assay, all parameters such as cells density $\left(6 \times 10^{5}\right.$ cells $\left./ \mathrm{mL}\right)$ and time of the treatment $(24 \mathrm{hrs})$ were constant throughout the whole experiment to assure stable and similar production of either $\mathrm{NO}$ or $\mathrm{ONOO}^{-}$.

The highest tested concentration of SNP $(4000 \mu \mathrm{M})$ decreased cell viability by almost $30 \%$ in case of K562 cells and almost $50 \%$ in case of 293 cells (Figure 10). Viability studies on K562 cells did not show any significant impact of SNP on cell growth rate except at the highest concentration of SNP. Concentrations of SNP at $2000 \mu \mathrm{M}$ resulted in only $16 \%$ loss of viability of K562 cells. However, 293 cells showed higher sensitivity toward SNP than that of K562 cells since their viability decreased significantly by 100 $\mu \mathrm{M}$ or greater concentrations of SNP. In contrast, SIN-1 showed a significant enhancing effect on $\mathrm{K} 562$ cell growth at concentrations as low as $10 \mu \mathrm{M}$ (Figure 11). In contrast, SIN-1 had no significant effect on 293 cells. Therefore, $50 \mu \mathrm{M}$ of SNP and $100 \mu \mathrm{M}$ of SIN-1 were chosen to treat 293 cells for all subsequent experiments.

The MTT assay was also preformed to assess whether CO has an effect on 293 cell viability. The data showed that both tested concentrations of CO (10 and $32 \%)$ have no effect on 293 cell viability (Figure 12). 
Figure 10: The decrease in cell viability (as measured by MTT assay) with the addition of increasing amounts of SNP to K562 and 293 cells incubated over 24 hrs at 6 X 105 cells/mL. Values are Means \pm SEM of six replicates for K562 and four replicates for 293 cells. $* * *$ Significantly different from controls at $\mathrm{p}<0.001$. Significance was tested using ANOVA followed by Tukey test. 


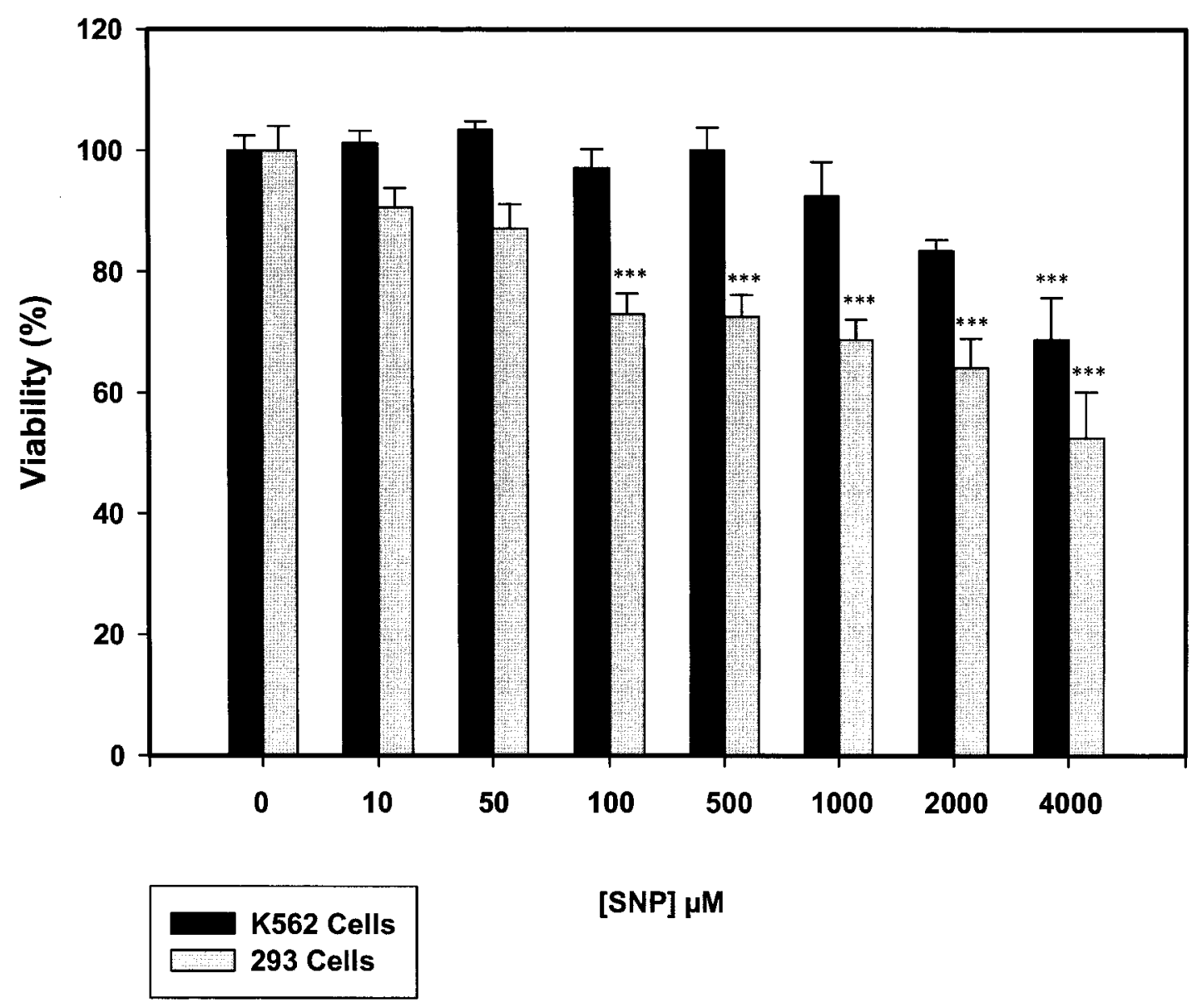


Figure 11: Cell viability (measured by MTT assay) showing the correlation between the growth of K562 and 293 cells with the addition of increasing amounts of SIN-1 after cells were treated and incubated for $24 \mathrm{hrs}(6 \times 105$ cells $/ \mathrm{mL})$. Values are Means \pm SEM of six replicates for K562 and four replicates for 293 cells. * Significantly different from control at $\mathrm{p}<0.05$ level, $* * *$ significantly different at $\mathrm{p}<0.001$ level according to ANOVA followed by Tukey test. 


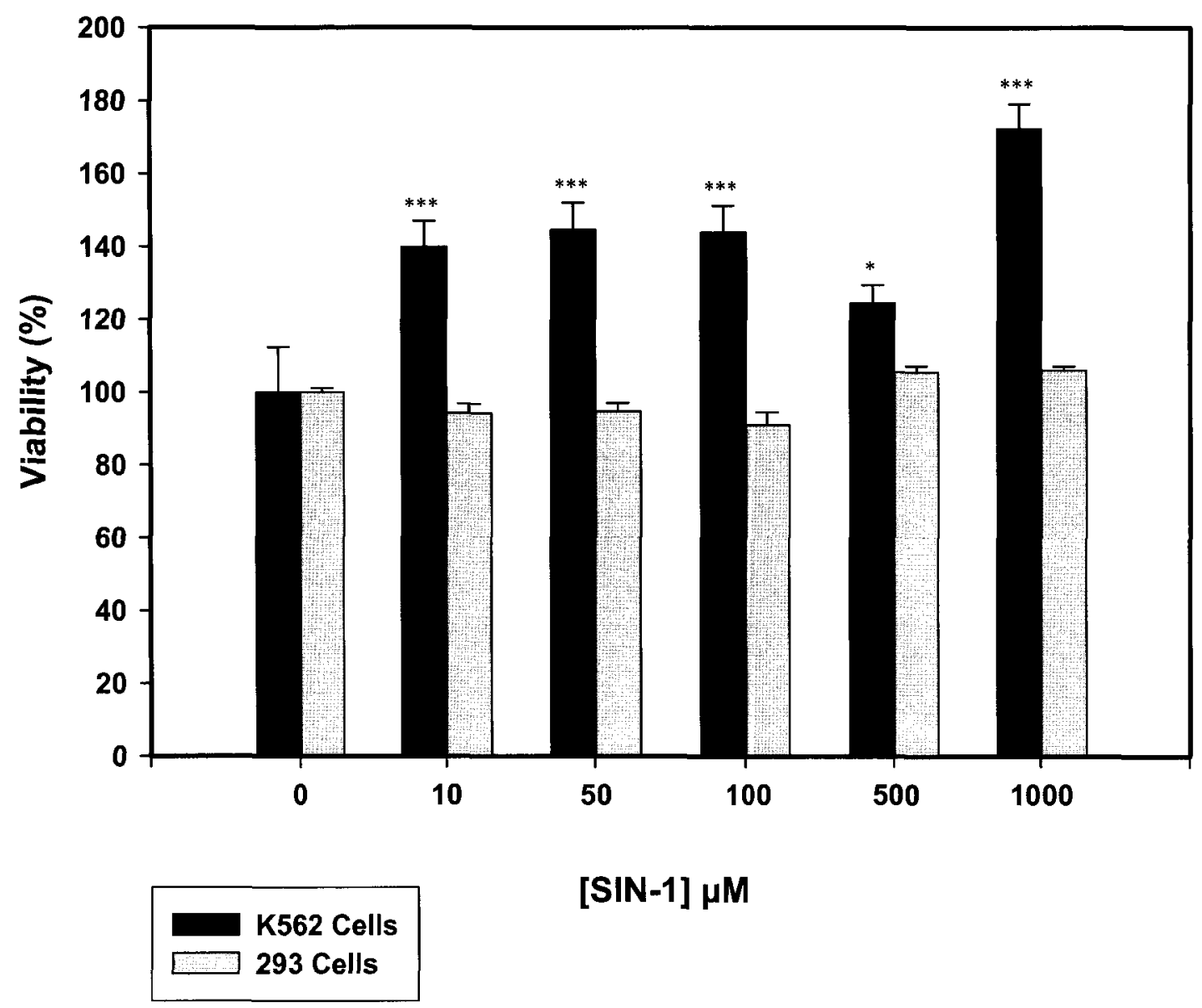


Figure 12: 293 cell viability (measured by MTT assay) following treatment with gas mixtures which include two different concentrations of $\mathrm{CO}(21 \% \mathrm{O} 2,10 \%$ of $\mathrm{CO}, 5 \%$ $\mathrm{CO}_{2}$, and balance $\mathrm{N}_{2}$ and $21 \% \mathrm{O}_{2}, 32 \%$ of $\mathrm{CO}, 5 \% \mathrm{CO}_{2}$, and balance $\mathrm{N}_{2}$ ) for over $24 \mathrm{hrs}$ $\left(6 \times 10^{5}\right.$ cells $\left./ \mathrm{mL}\right)$. Values are Means $\pm \mathrm{SEM}$ of eight replicates. 


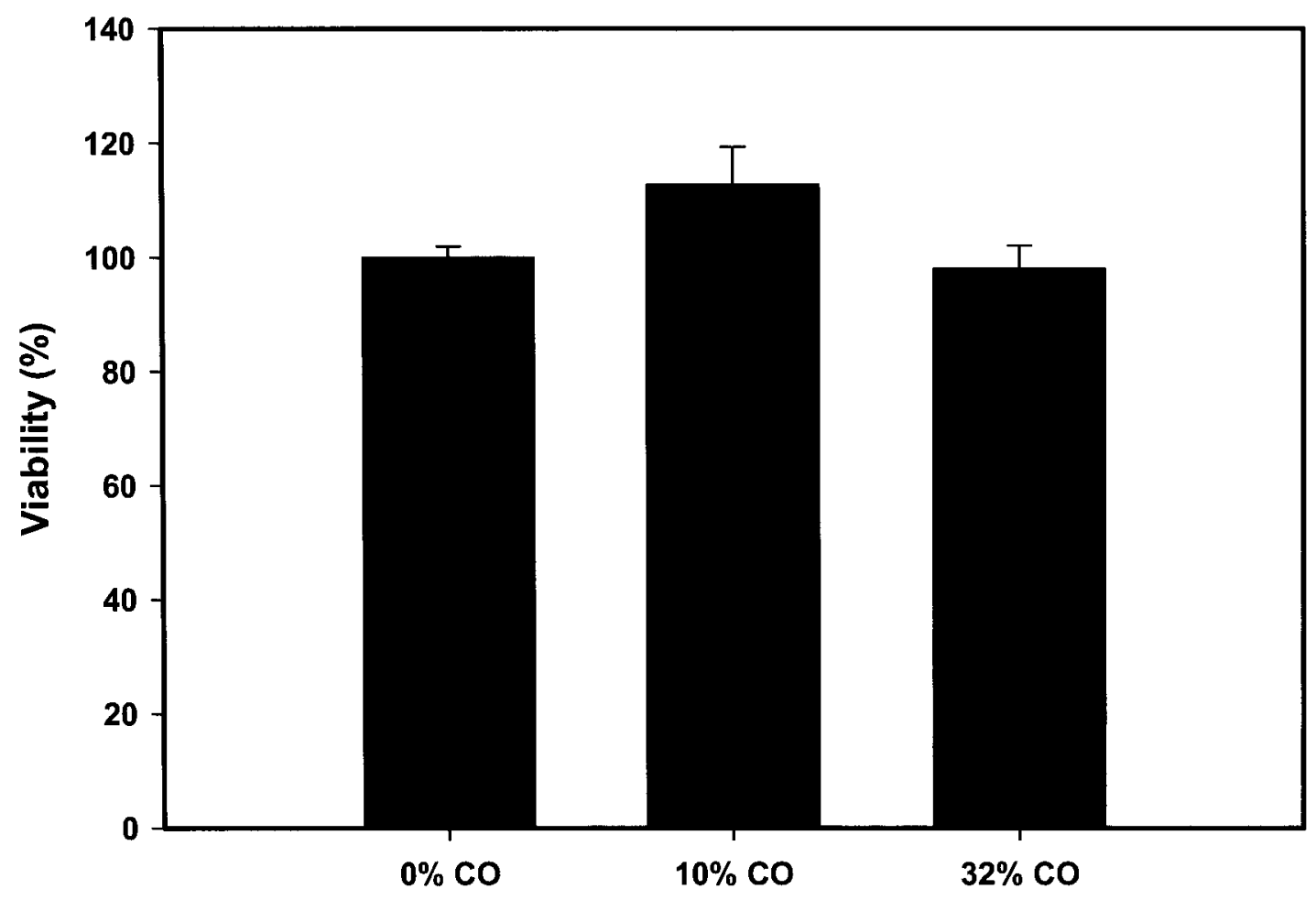




\subsection{Time Course}

The correlation between time and ALAS2 expression and mitochondrial import was investigated by conducting a time course experiment for $72 \mathrm{hrs}$ in order to observe the premature (pre-import) and mature forms (post-import and processed) of recombinant ALAS2 (Figure 13). 293 cells were transiently transfected with $0.8 \mu \mathrm{g}$ of plasmidDNA expressing double FLAG-tagged premature ALAS2 and harvested at various time points $(0,1,2,4,6,12,24,48,72 \mathrm{hrs})$. Whole cell extracts were analysed by Western blot and expressed FLAG-tagged proteins were detected by anti-FLAG HRP antibody. Western blot analysis shows that ALAS2 was not expressed up to $6 \mathrm{hrs}$ after the transient transfection. Although there was no mitochondrial import, 293 cells started to express the premature form of ALAS2 by $12 \mathrm{hrs}$ after the transient transfection. The optimum expression and mitochondrial import of ALAS2 was obtained after 24 hrs of transfection. However, both import and expression decreased after 24 hrs and FLAG-tagged protein was completely absent by 72 hrs post-transfection.

\subsection{Optimization of DNA Concentration for Transfection into 293 Cells}

Following establishment of time, it was essential to assess the concentration of transiently transfected DNA that results in the maximal expression of both forms of ALAS2. It was also critical to achieve this goal without decreasing cell viability, as high 
Figure 13: ALAS2 expression, mitochondrial import and processing after a time course of $0,1,2,3,4,5,6,12,24,48$ and 72 hrs post-transfection. Data is presented as IDV values determined by densitometry analysis: the solid curve indicates wildtype premature ALAS2 and the dotted curve indicates mature ALAS2. 


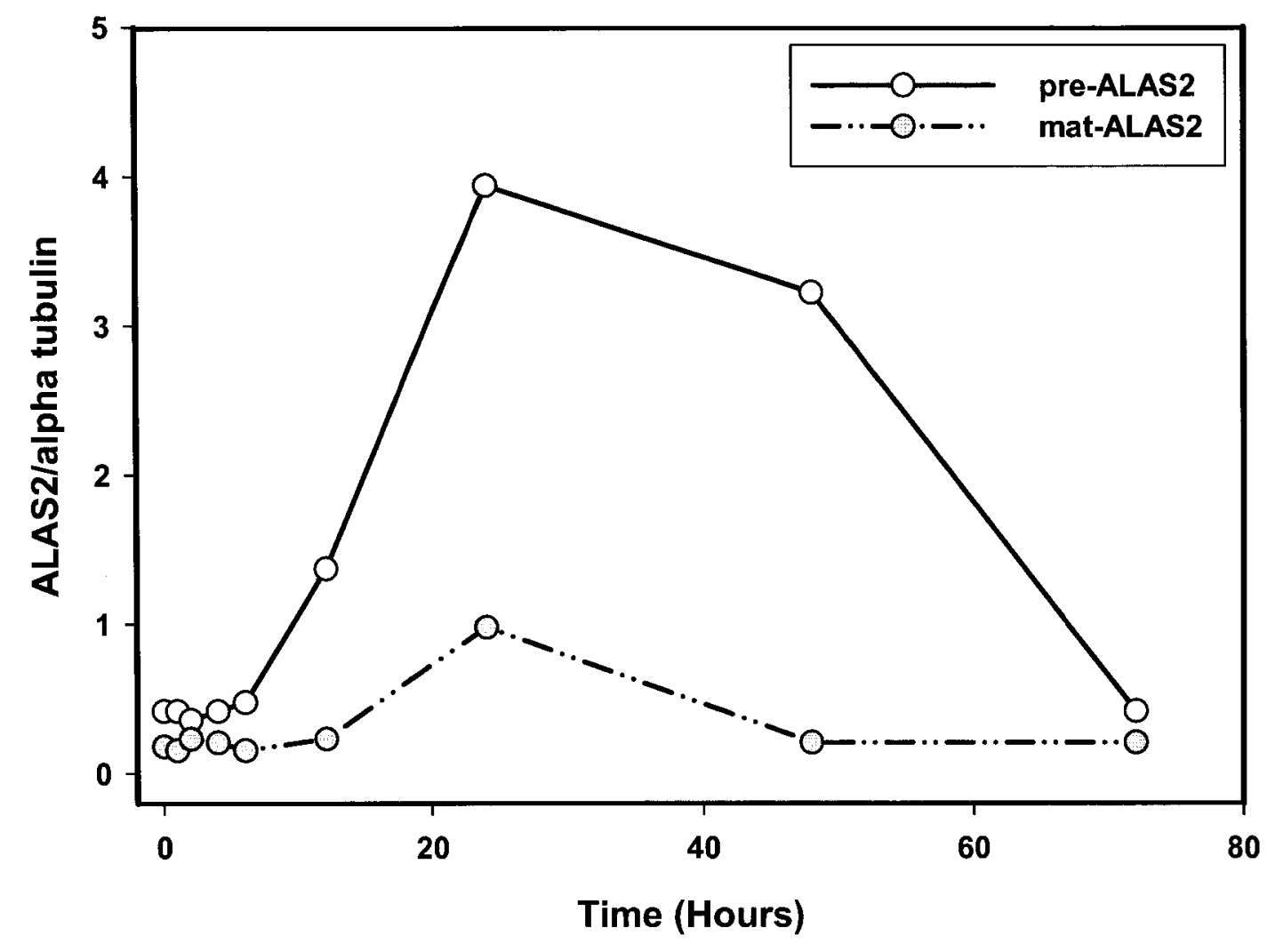


concentrations of nucleic acids are detrimental to cells. Various concentrations of DNA $(0.0,0.2,0.4,0.6,0.8,1.0 \mu \mathrm{g})$ were transiently transfected into 293 cells for $24 \mathrm{hrs}$, harvested and whole cell extracts were prepared (Figure 14). Untransfected 293 cells showed no expression or mitochondrial import at all whereas $0.2,0.4$, and $0.6 \mu \mathrm{g}$ of DNA resulted in ALAS2 expression with no import detected by anti-FLAG HRP antibody. On the other hand, 0.8 and $1.0 \mu \mathrm{g}$ expressed similar amounts of ALAS2 according to band density but $1 \mu \mathrm{g}$ of transfected DNA had the greatest amount of mitochondrial import. Thus, $1 \mu \mathrm{g}$ of plasmid was chosen as the optimum DNA concentration for transient transfections. Mature ALAS2 was included as a positive control and expressed a protein band of similar molecular weight as processed premature ALAS2. It was also noticed that concentrations of DNA above $1 \mu \mathrm{g}$ was toxic to cells and resulted in lower amounts of expressed protein.

\subsection{Heme and ALAS2 Mitochondrial Import}

The main objective of this assay was to determine whether heme binding to the leader sequence of the double FLAG-tagged wildtype ALAS2 can inhibit the import of premature ALAS2 into the mitochondria as a feedback mechanism of heme synthesis. 293 cells were transiently transfected and treated with different concentrations of hemin for 24 hrs (Figure 15). The final concentrations of hemin in the cell culture medium was $0,5,10,15,25,35,45$ and $55 \mu \mathrm{M}$. Western blot data demonstrated that expression and 
Figure 14: Western of blot of whole cell extracts of wildtype premature ALAS2 expressed in 293 and detected by anti-FLAG-HRP antibody. Band densities were normalized to $\alpha$ tubulin expression. Lane 1, untransfected 293 cells; Lane 2, cells transfected with $0.2 \mu \mathrm{g}$ DNA; Lane 3, cells transfected with $0.4 \mu \mathrm{g}$ DNA Lane 4, cells transfected with $0.6 \mu \mathrm{g}$ DNA Lane 5, cells transfected with $0.8 \mu \mathrm{g}$ DNA Lane 6, cells transfected with $1 \mu \mathrm{g}$ DNA Lane 7, cells transfected with $0.4 \mu \mathrm{g}$ DNA mature ALAS2 as a positive control; $p=$ premature ALAS2 and $m=$ mature ALAS2. 


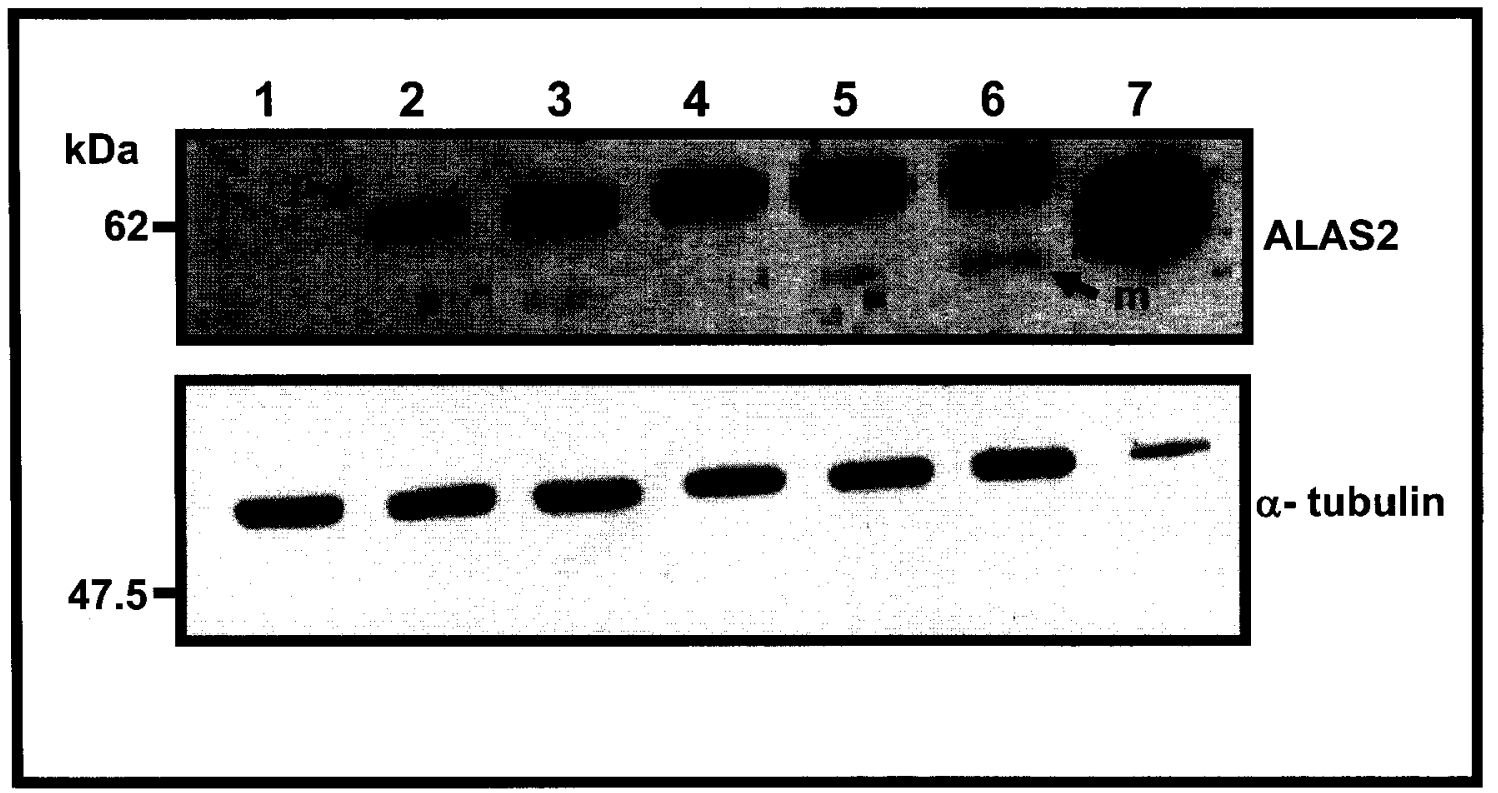


Figure 15: Western blots of wildtype premature ALAS2 expressed in 293 cells, treated with different concentrations of hemin for $24 \mathrm{hrs}$, and detected by anti-FLAG-HRP antibody. Levels of FLAG protein were normalized to $\alpha$ tubulin. Lane 1, untreated (normoxia) transfected 293 cells; Lane 2, cells treated with $5 \mu \mathrm{M}$ hemin; Lane 3, cells treated with $10 \mu \mathrm{M}$ hemin; Lane 4, cells treated with $15 \mu \mathrm{M}$ hemin; Lane 5, cells treated with $25 \mu \mathrm{M}$ hemin; Lane 6, cells treated with $35 \mu \mathrm{M}$ hemin; Lane 7, cells treated with $45 \mu \mathrm{M}$ hemin; Lane 8, cells treated with $55 \mu \mathrm{M}$ hemin. Values on top of each bar are ratios of ALAS2 expression to $\alpha$ tubulin expression. 
A

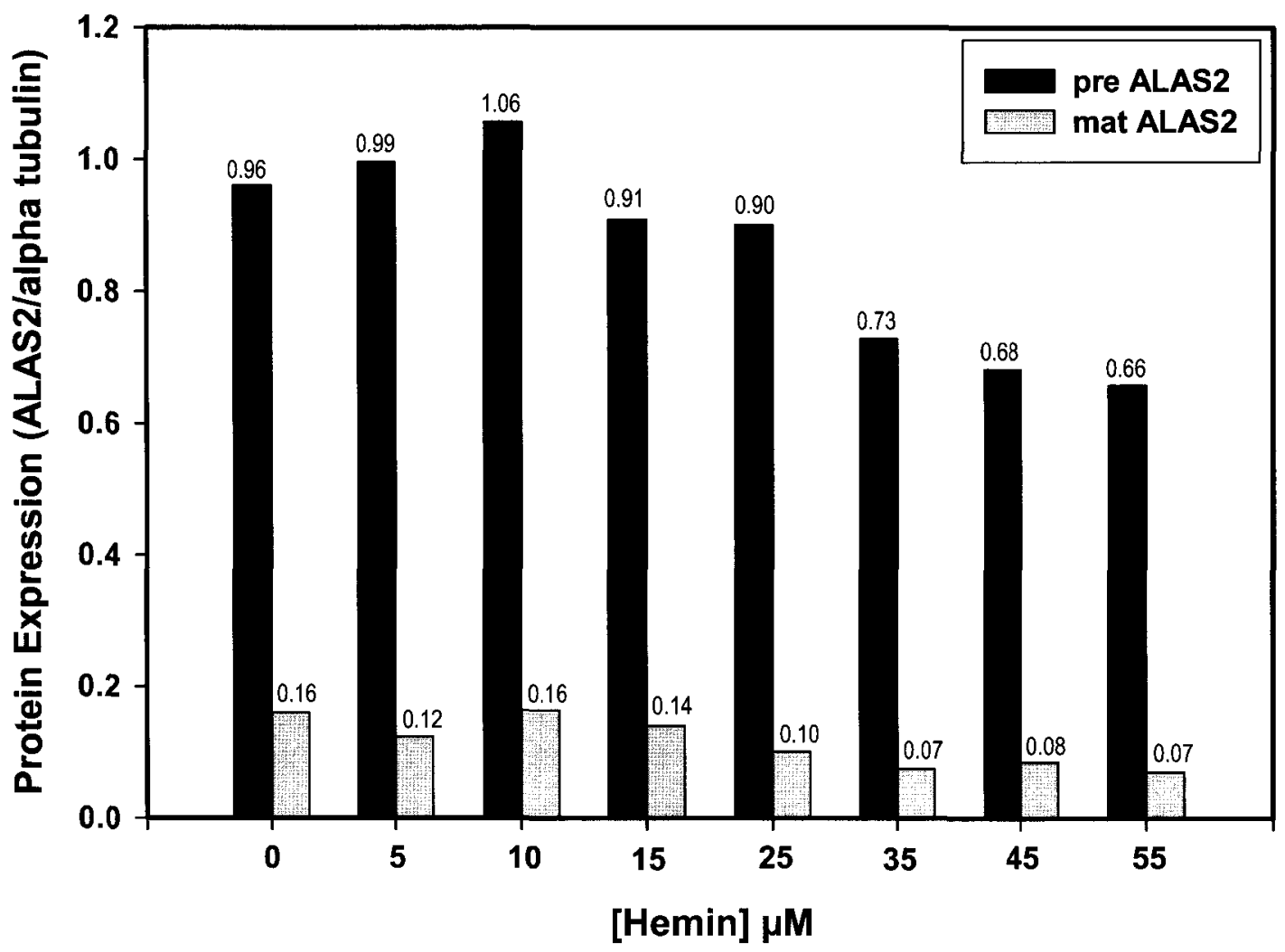

B

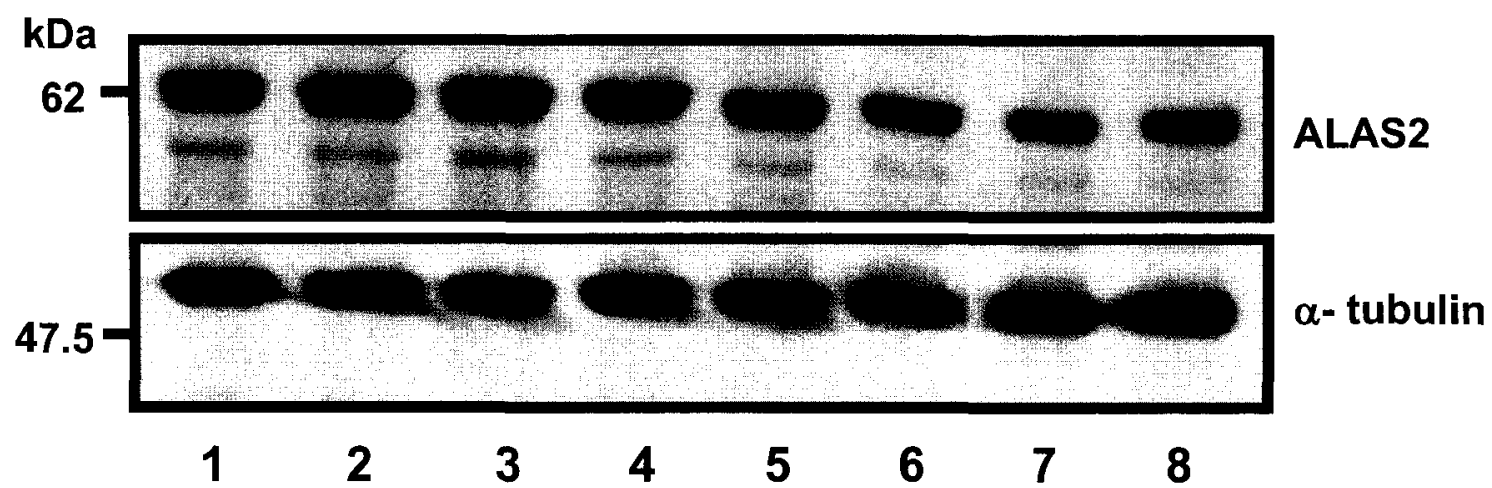


mitochondrial import of ALAS2 remained almost the same for $0,5,10,15$, and $25 \mu \mathrm{M}$ implying that $25 \mu \mathrm{M}$ of hemin could not inhibit the import of ALAS2 into the mitochondria while higher concentrations of hemin decreased both expression and mitochondrial import.

\subsection{Hypoxia and Hypoxic Mimetic Treatments}

Like HIF $\alpha$, wildtype ALAS2 contains a LXXLAP sequence which stabilizes the protein under hypoxia and proteasome inhibitor conditions. It was also demonstrated previously that some metals can mimic hypoxia and stabilize HIF $\alpha$. We tested hypoxic mimics such as cobalt chloride $\left(\mathrm{CoCl}_{2}\right)$, deferroxamine (DFO) and proteasome inhibitor (PI) to identify if they influence the expression and mitochondrial import of wildtype ALAS2 in a similar manner to hypoxia. As shown in Figure 16A and 16B, hypoxia itself has a significant impact on wildtype ALAS2. Hypoxia decreased both the expression and mitochondrial import of ALAS2 while $100 \mu \mathrm{M} \mathrm{CoCl}_{2}, 100 \mu \mathrm{M}$ DFO and $10 \mu \mathrm{M}$ PI have no significant effect on ALAS2 expression and mitochondrial import under normoxic conditions. 
Figure 16 A) Hypoxic mimetic treatments, bars correspond to Means of three replicate experiments \pm SEM of wildtype premature ALAS2 protein expression and mitochondrial import after transient transfection and 24 hrs of treatment. Figure 16 B) A representative Western blot of whole cell extracts of premature ALAS2 expressed in 293 using antiFLAG-HRP antibody and normalized to $\alpha$-tubulin expression Lane 1, normoxia $(21 \%$ $\left.\mathrm{O}_{2}, 5 \% \mathrm{CO}_{2}, 37^{\circ} \mathrm{C}\right)$; Lane 2, hypoxia $\left(1 \% \mathrm{O}_{2}, 5 \% \mathrm{CO}_{2}, 37^{\circ} \mathrm{C}\right)$; Lane 3, $10 \mu \mathrm{M}$ PI; Lane

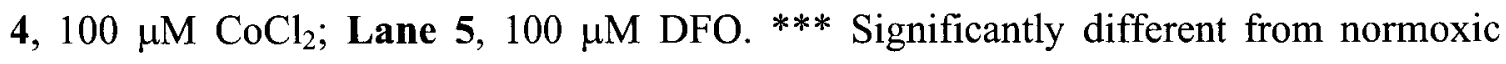
conditions $\left(21 \% \mathrm{O}_{2}\right)$ at $\mathrm{p}<0.001$, according to ANOVA followed by Tukey test. 
A

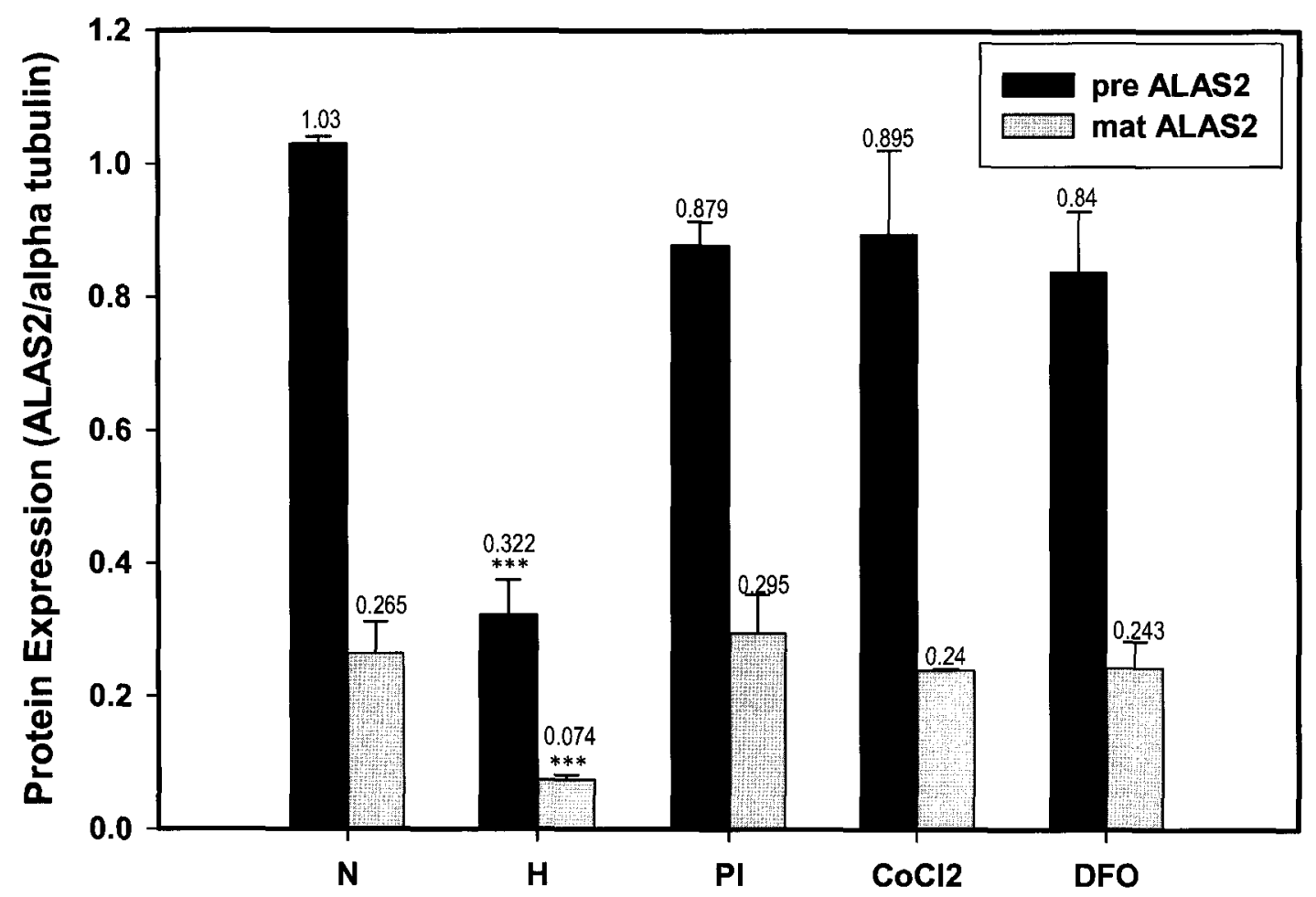

B

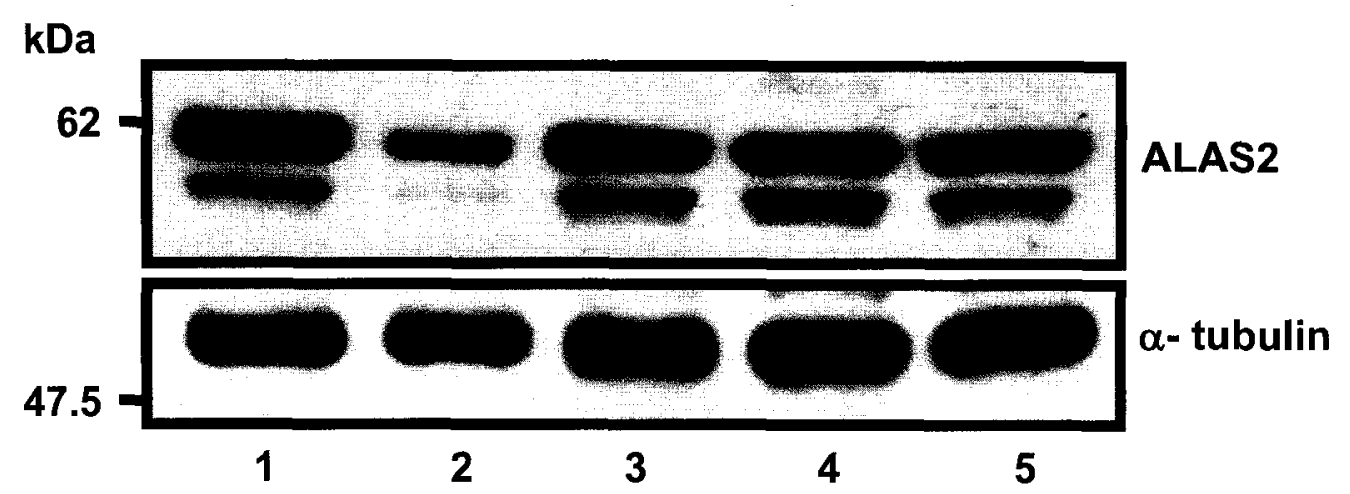




\subsection{Nitric Oxide Treatments}

The effect of $\mathrm{NO}$ and $\mathrm{ONOO}^{-}$, formed chemically by SNP and SIN-1 respectively, was investigated in the presence and the absence of $\mathrm{O}_{2}$. The data (Figure 17A and 17B) shows a significant decrease in the expression and mitochondrial import of wildtype ALAS2 when it was treated with SNP for $24 \mathrm{hrs}$ under normoxic conditions $\left(21 \% \mathrm{O}_{2}, 5 \%\right.$ $\mathrm{CO}_{2}, 37^{\circ} \mathrm{C}$ ) whereas SIN-1 had no effect on the expression of ALAS2 but had a significant inhibitory effect on the mitochondrial import of ALAS2. Simultaneously, the same experiment was preformed under hypoxia $\left(1 \% \mathrm{O}_{2}, 5 \% \mathrm{CO}_{2}, 37^{\circ} \mathrm{C}\right)$. The data showed that hypoxic treatment decreased both the expression and the import of wildtype ALAS2 in 293 cells significantly which agreed and further confirmed the effect of hypoxia alone in the previous experiment (Figure 16). A combination of hypoxia with either SNP or SIN-1 also resulted in a decrease in expression and mitochondrial import of ALAS2 similar to the effect of hypoxia alone.

\subsection{Mitochondrial Isolation}

As evidence of mitochondrial import of ALAS2, mitochondria were isolated from transiently transfected 239 cells as described above. Data confirmed that not only wildtype premature ALAS2 is imported into the mitochondria by the import system but also that it is cleaved. Figure 18A shows isolated mitochondrial fractions under different treatments. Recombinant ALAS2 expression in 293 cells under normoxia or following 
Figure 17 A) NO and $\mathrm{ONOO}^{-}$donor treatments under normoxic and hypoxic conditions. Bars correspond to Means of three replicate experiments \pm SEM of wildtype premature ALAS2 expression and mitochondrial import after $24 \mathrm{hrs}$ of treatment. Figure 17 B) A representative Western blot of premature ALAS2, detected with anti-FLAG-HRP, from 293 whole cell extracts after $24 \mathrm{hrs}$ of SNP and SIN-1 treatment and normalized to $\alpha$ tubulin. Lane 1, normoxia; Lane 2, normoxia + SNP; Lane 3, normoxia + SIN-1; Lane 4, hypoxia; Lane 5, hypoxia + SNP; Lane 6, hypoxia + SIN-1. Values on top of each bar are Means of the ratios of ALAS2 expression to $\alpha$-tubulin expression. ** Significantly different from normoxic $\left(21 \% \mathrm{O}_{2}\right)$ conditions at $\mathrm{p}<0.01$ level, $* * *$ Significantly different from normoxic $\left(21 \% \mathrm{O}_{2}\right)$ conditions at $\mathrm{p}<0.001$ level according to one-way ANOVA followed by Tukey test. \# Significantly different from normoxic $\left(21 \% \mathrm{O}_{2}\right)$ group of treatments at $p<0.001$ level according to two-way ANOVA followed by Tukey test. 
A

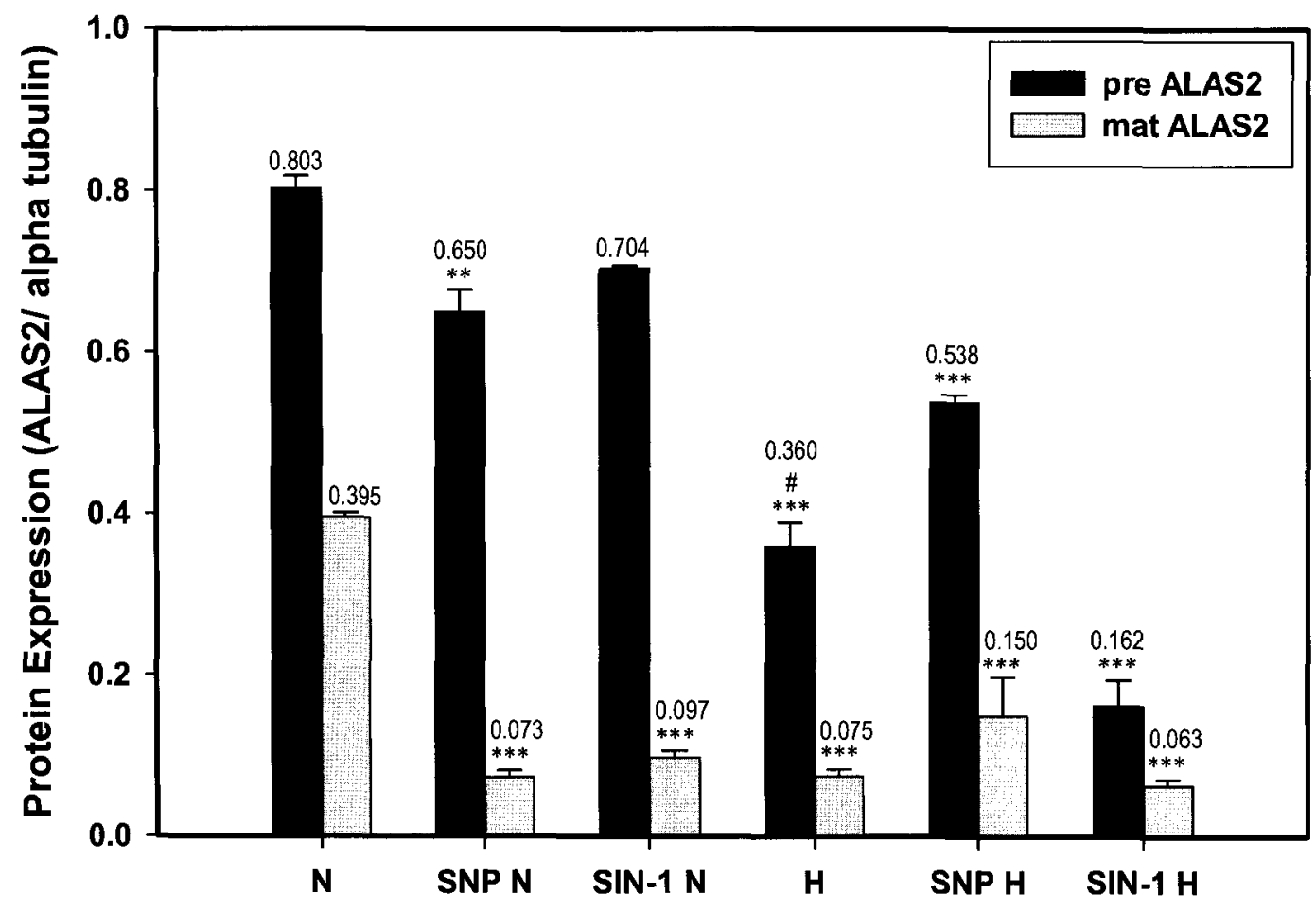

B

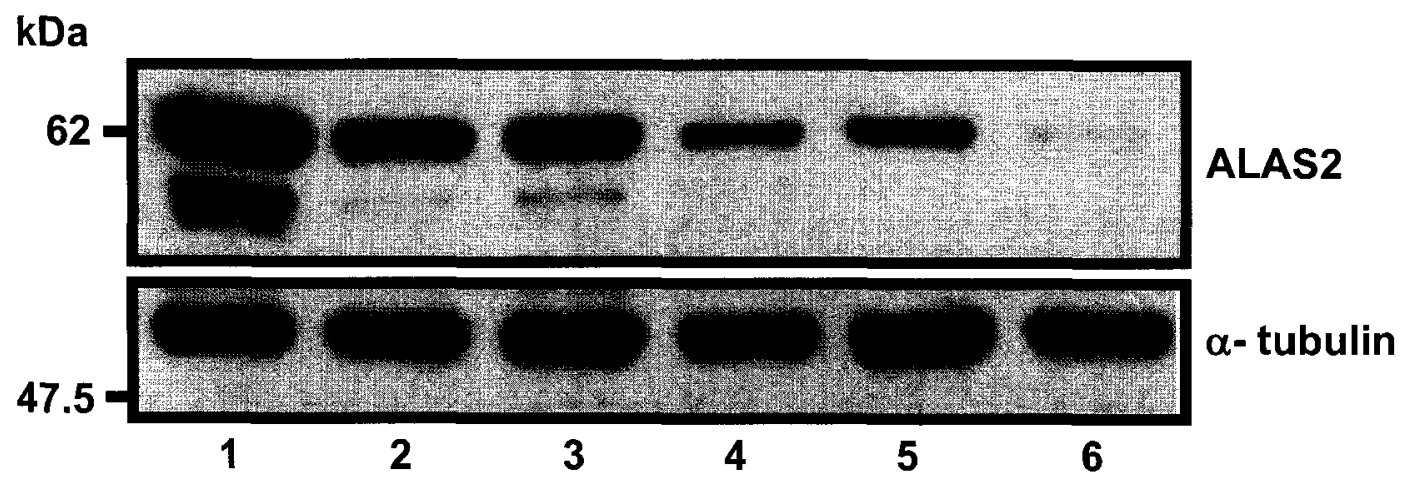


Figure 18 A) Western blot of isolated mitochondria from 293 cells using anti-FLAGHRP. Figure 18 B) PCR amplification of Figure A treatments to assess the mitochondrial purity utilizing mtDNA (222 b.p.) and $\beta$-globin ( 83 b.p.) primers. Lane 1 , normoxia (Nor); Lane 2, normoxia + SNP; Lane 3, normoxia + SIN-1; Lane 4, hypoxia (Hyp); Lane 5, hypoxia + SNP; Lane 6, hypoxia + SIN-1. The lanes are in the same order in Parts $\mathrm{A}$ and $\mathrm{B}$ of the Figure. 

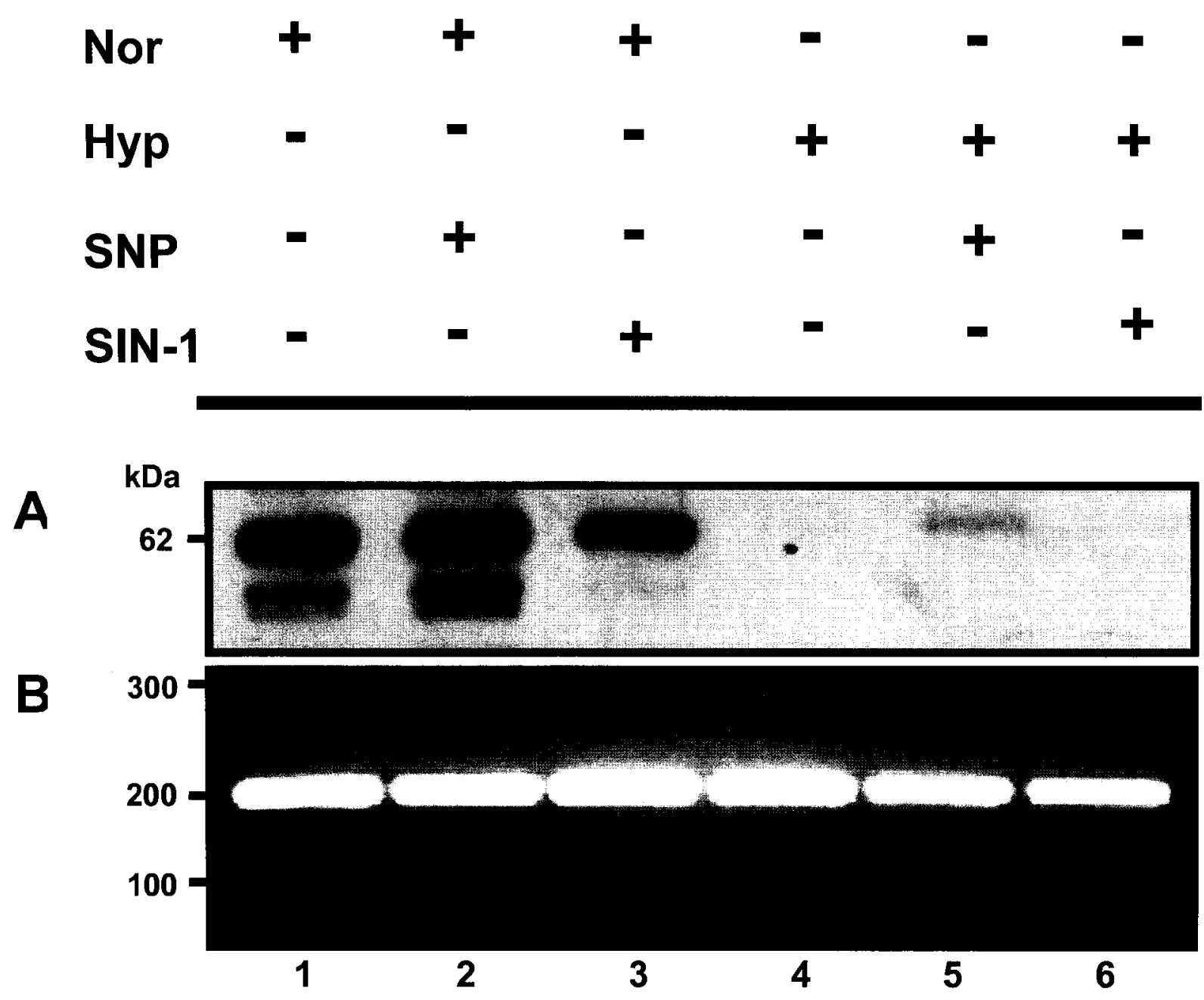
SNP treatment under the same conditions was similar but more mature ALAS2 occurred with SNP treatment as shown in Lane 2. SIN-1, however, could completely inhibit ALAS2 processing (Lane 3). Moreover, cells treated with SIN-1 imported less ALAS2 than cells treated with SNP under normoxic conditions. Cells treated with hypoxia or hypoxia with SIN-1 showed sever inhibition and were incapable of either importing or processing ALAS2. Cells treated with SNP under hypoxic conditions show very low levels of ALAS2 import without processing. Figure 18B shows that isolated mitochondria from transiently transfected 239 cells were pure by PCR amplification of mtDNA (222 b.p.) and cytosolic $\beta$-globin ( 83 b.p.) genomic fragments.

\subsection{Carbon Monoxide Treatment}

In order to evaluate the influence of $\mathrm{CO}$ on the expression and mitochondrial import of wildtype premature ALAS2 under normoxic and hypoxic conditions, a unique experimental setup was designed to treat transiently transfected 293 cells with different gas mixtures, including 10 and $32 \% \mathrm{CO}$. The data shown in Figure 19 demonstrates that under normoxic conditions $\left(21 \% \mathrm{O}_{2}, 10 \%\right.$ or $32 \%$ of $\mathrm{CO}, 5 \% \mathrm{CO}_{2}$, and balance $\left.\mathrm{N}_{2}\right)$ there is no significant change in the expression of ALAS2 after 24 hrs of treatment, regardless of low or high concentrations of $\mathrm{CO}$, whereas mitochondrial import and processing was significantly inhibited by $\mathrm{CO}$ treatment. Higher concentrations of $\mathrm{CO}$ resulted in the general trend of decreased levels of both premature and mature ALAS2 as seen on the 
Figure 19 A) CO treatments under normoxic and hypoxic conditions respectively. Bars correspond to Means of three replicate experiments \pm SEM of wildtype premature ALAS2 expression and import after 24 hrs of treatment. Figure 19 B) A representative Western blot of whole cell extracts of 293 cells treated with CO for 24 hrs. Shown is premature ALAS2 using anti-FLAG-HRP and normalized to $\alpha$-tubulin. Lane 1, normoxia (N); Lane 2, normoxia + $10 \% \mathrm{CO}$; Lane 3, normoxia + $32 \% \mathrm{CO}$; Lane 4, hypoxia $(\mathrm{H})$; Lane 5, hypoxia $+10 \% \mathrm{CO}$; Lane 6 , hypoxia $+32 \% \mathrm{CO}$. Values on top of each bar are Means of the ratios of ALAS2 expression to $\alpha$-tubulin expression. ** Significantly different from normoxic $\left(21 \% \mathrm{O}_{2}\right)$ conditions at $\mathrm{p}<0.01 * * *$ Significantly different from normoxic $\left(21 \% \mathrm{O}_{2}\right)$ conditions at $\mathrm{p}<0.001$ level according to one-way ANOVA followed by Tukey test. \# Significantly different from normoxic $\left(21 \% \mathrm{O}_{2}\right)$ group of treatments at $p<0.001$ level according to two-way ANOVA followed by Tukey test. 


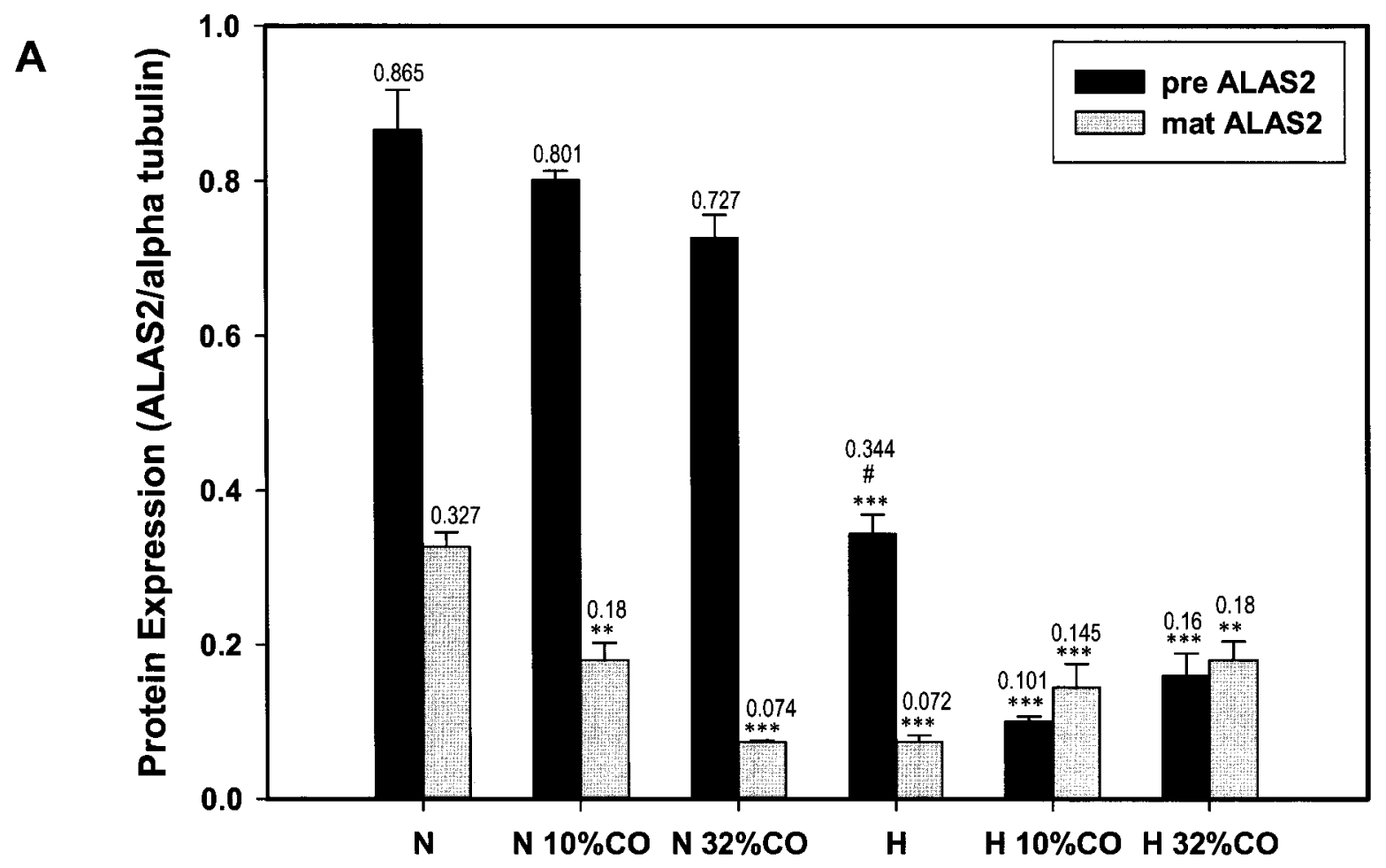

B $\quad k D a$

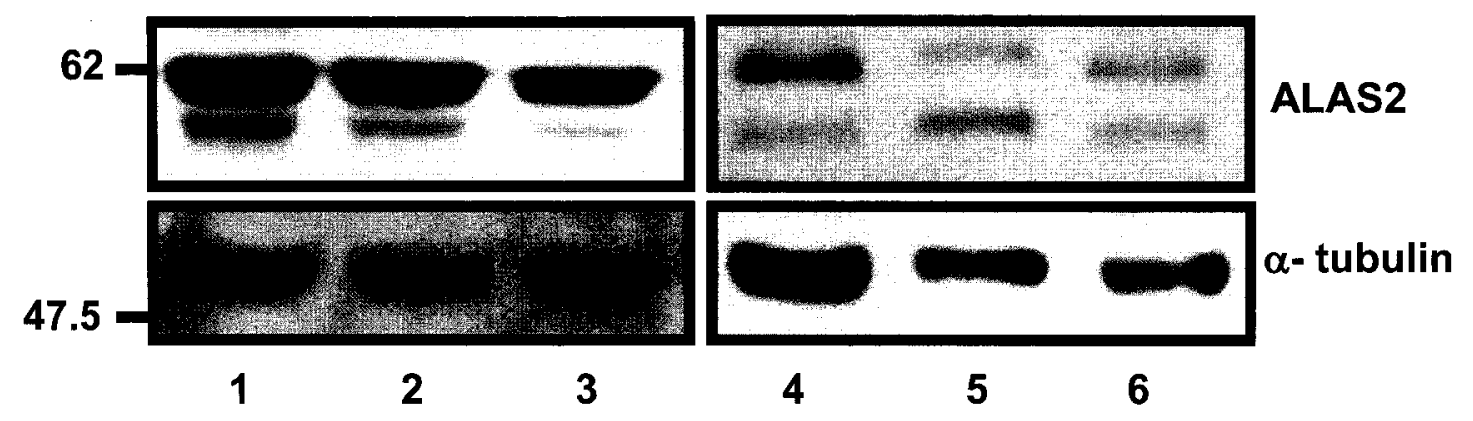


Western blot. Interesting findings were found with the combination of $\mathrm{CO}$ and hypoxia treatments $\left(1 \% \mathrm{O}_{2}, 10 \%\right.$ or $32 \%$ of $\mathrm{CO}, 5 \% \mathrm{CO}_{2}$, and balance $\left.\mathrm{N}_{2}\right)$. Decreases in both the expression and mitochondrial import of ALAS2 were significant as shown in Figure 19 for hypoxia alone or in combination with $\mathrm{CO}$.

\section{DISCUSSION}

This study demonstrates that the mitochondrial transport of wildtype premature ALAS2 is inhibited after hypoxia, $\mathrm{NO}, \mathrm{ONOO}^{-}$and $\mathrm{CO}$ treatments in comparison to normoxic treatment. The additive effect of hypoxia to the above indicated treatments showed stronger inhibitory impact on both the expression and the transport of the wildtype premature ALAS2 that is expressed in non-erythroid cells.

\subsection{Viability Study}

The MTT assay was employed to determine cell viability under different concentrations of NO donors (Figures 10 and 11) as well as selected concentrations of CO (Figure 12). Since cell viability may have been affected by such treatments, it was critical to perform viability studies in order to determine the non lethal concentrations of both gas molecules. Viability tests were carried out on both K562 and 293 cell lines. The chief aim of treating with $\mathrm{NO}$ and $\mathrm{CO}$ is to investigate their effect on the overall expression of wildtype premature ALAS2 and particularly its import under various environmental conditions. 
We established a range of concentrations of SNP treatments $(10-4,000 \mu \mathrm{M})$ to test on cell lines based on the studies of Che'nais et al. (1999) where they treated K562 cells with $25-100 \mu \mathrm{M}$ of SNP. We tested both higher and lower concentrations than the ones used by this group. In this study, they found that the growth rate of K562 cells was not affected with treatment of up to $1 \mathrm{mM}$ of SNP (at which the viability was 95\%) (Che'nais et al., 1999). The highest concentration of SNP used in our experiments was $4000 \mu \mathrm{M}$ in order to achieve the highest possible concentration of SNP without affecting cell viability. A significant reduction in 293 cell viability was observed starting from 100$4,000 \mu \mathrm{M}$ of SNP whereas a significant reduction of K562 viability was only observed at $4,000 \mu \mathrm{M}$ SNP. Therefore, $50 \mu \mathrm{M}$ of SNP was chosen as the optimal concentration to treat cells with in further studies. The effect of SIN-1 $(0-1000 \mu \mathrm{M})$ on the viability of both cell lines was also tested. SIN-1 did not affect the viability of either cell line (Figure 11) however it had a beneficial effect on $\mathrm{K} 562$ growth. It was therefore decided to treat cells with $100 \mu \mathrm{M}$ of SIN-1 for all subsequent experiments. This concentration of SNP was much lower than the optimal concentration used in the Che'nais et al. (1999) study.

\subsection{Time Course of ALAS2 Expression and Mitochondrial Import}

Since it is critical to obtain data at optimal experimental conditions, we conducted a time course experiment in order to determine the optimal time of expression of wildtype premature ALAS2 in transient transfection studies. The following time points, from the time of transfecting cells with ALAS2 expression plasmids, were chosen to follow the expression of wildtype premature ALAS2: 0, 1, 2, 4, 6, 12, 24, 48 and $72 \mathrm{hrs}$ following 
transfection under normoxic conditions $\left(21 \% \mathrm{O}_{2}, 5 \% \mathrm{CO}_{2}, 37^{\circ} \mathrm{C}\right)$. As shown in Figure 13, cellular intake of plasmid DNA occurred over the first four hours post-transfection and by $12 \mathrm{hrs}$, cells began to express and process recombinant FLAG-tagged ALAS2. The optimal expression and import of wildtype premature ALAS2 in 293 cells was obtained 24-28 hrs post-transfection, after which protein expression decreased and was completely absent by 72 hrs of post-transfection. This concurred with previous data from the Willmore lab (Abu-Farha et al. 2005) in which recombinant ALAS2, expressed in K562 cells, had a normoxic turnover time of approximately $36 \mathrm{hrs}$. This also concurred with the manufacturer's protocol for the transfection reagent (Lipofectamine 2000, Invitrogen, Carlsbad, CA) which suggested the minimal incubation time after transfection to be 24 hrs.

\subsection{DNA Concentration and ALAS2 Expression and Mitochondrial Import}

The relationship between the concentrations of transiently transfected plasmid DNA and the expression and mitochondrial import of premature ALAS2 was investigated. We tested $0.0,0.2,0.4,0.6,0.8,1.0 \mu \mathrm{g}$ of our doubly FLAG-tagged wildtype premature ALAS2 (Figure 14) for $24 \mathrm{hrs}$ in a total volume of $500 \mu \mathrm{L}$ of cell media. Initially, we hypothesized that there was a correlation between the amount of transiently transfected DNA, the amount of recombinant protein expressed and the mitochondrial import and processing of the recombinant protein. In other words, low concentrations of expressed protein might generate higher concentrations of the processed form as mitochondrial 
import may be saturable. However, the result (Figure 13) showed that with more DNA transfected into 293 cells, the more mature ALAS2 is formed up to $1 \mu \mathrm{g}$.

\subsection{Heme Association with Premature ALAS2}

Heme has previously been reported to associate with the leader sequence of premature ALAS2 (Lathrop and Timko, 1993). A second, more recent study, suggested that this was not the case (Munakata et al., 2004). The binding of heme to the leader sequence of ALAS would prevent its import into the mitochondria and thus provides an elegant feedback mechanism to prevent the overproduction of heme in cells. The possibility of heme association with the leader sequence of wildtype premature ALAS2 was tested by treating transiently transfected 293 cells with different concentrations of hemin $(0,5,10,15,20,25,35,45$ and $55 \mu \mathrm{M})$ for $24 \mathrm{hrs}$. The results of this experiment demonstrated that heme had no effect on the mitochondrial import of wildtype premature ALAS2 (Figure 14). Our data validates and supports the more recent study done by Munakata et al. (2004) where they found that heme is not implicated in the inhibition of the mitochondrial import of ALAS2 in vivo. In contrast, the study by Lathrop and Timko (1993) presented evidence that heme mediates the inhibition of ALAS2 mitochondrial import. The question remains as to why heme cannot inhibit the import of ALAS2 in vivo? Munakata et al. (2004) discussed their discrepancies with the earlier study: "Although their results (referring to Lathrop and Timko study) seem to contradict our study, Lathrop and Timko used in vitro systems, whereas here we used an in vivo system. Thus, the different results may be due to the experimental conditions. The heme 
inhibition of the transport of mouse ALAS2 may also differ from that of rat ALAS2. Another possibility is that the positions of the HRMs in the protein may affect the inhibitory activity of heme. It should also be pointed out that the hemin concentration in our case is the concentration in the growth medium, not in the cell, and as such is considered to be lower than the concentration used in the in vitro experiments of Lathrop and Timko. If the heme concentration in the cell were increased to the levels used under in vitro conditions, then inhibition of ALAS2 transport might occur".

Unlike the controversy as to whether ALAS2 mitochondrial import is inhibited by heme or not, it is well established that the mitochondrial import of ALAS1, the nonerythorid isoform of the enzyme, can be inhibited by heme both in vivo and in vitro (Dailey et al., 2005; Munakata et al., 2004; Goodfellow et al., 2001). To our knowledge, there is not a signal recent study that provides strong evidence that mitochondrial import of premature ALAS2 is inhibited by heme in vivo. It is logical that wildtype premature ALAS2 is not inhibited by heme in erythroid cells during erythropoiesis, the process of development of red blood cells through several stages of cell division and differentiation (Abu-Farha et al., 2005), since high levels of functional ALAS2 is required to produce heme for hemoglobin. ALAS1, known as the housekeeping isoform, induces heme synthesis for cytochromes and non-hemoglobin proteins to maintain limited cellular heme concentration (Hunakata et al., 2004). Induction of this isoform may not be to the same extent during non-erythroid cell differentiation. 


\subsection{Hypoxia, Hypoxic Mimics and Mitochondrial Import}

The role of hypoxia and hypoxic mimics namely $\mathrm{CoCl}_{2}, \mathrm{DFO}$, and PI was investigated to verify the effect of such treatments on the wildtype premature ALAS2 expression and import. It is well established that HIF-1 $\alpha_{2}$ which has the same LXXLAP sequence as the wildtype ALAS2, can be stabilized by hypoxia, PI (Abu-Farha et al., 2005) and $\mathrm{CoCl}_{2}$ (Hervouet et al., 2006) (Figure 2). Our results showed (Figure 16) that the expression and import of wildtype premature ALAS2 is stabilized by normoxia and significantly inhibited by hypoxia. Although the effect of hypoxic mimics is not significantly different from untreated cells, according to ANOVA analysis, it remains relevant to the inhibitory effect of hypoxia. Our findings in this study, especially regarding the expression and mitochondrial import of the premature ALAS2 under normoxic compared to hypoxic conditions, seem to be contradicting the findings of AbuFarha et al., 2005 study where they concluded that mature ALAS2 is stabilized by hypoxia and proteasome inhibition. These conflicting results can be mainly due to the type of cell lines used in the study since Abu-Farha et al. (2005) used differentiated K562 cells which have the ability to develop to red blood cells during erythropoiesis. However, in this study we used 293 cells which cannot synthesize ALAS2 endogenously in order to avoid any background synthesis of ALAS2. Moreover, 293 cells are well known for their expression quality being greater than $90 \%$. It seems to be justified that hypoxia does not stabilize ALAS2 which is expressed in non-erythroid cells like 293 since one of the most important means to adapt to hypoxia is to increase $\mathrm{O}_{2}$ transport to tissues and vital organs 
which can be only achieved by developing differentiated erythroid cells such as K562 cells to mature red blood cells.

\subsection{NO and ALAS2 Expression and Mitochondrial Import}

The effects of gas molecules other than $\mathrm{O}_{2}$ such as $\mathrm{NO}, \mathrm{ONOO}^{-}$and $\mathrm{CO}$, which may affect ALAS2 mitochondrial transport, were of interest to study. In order to investigate the effect of $\mathrm{NO}$ and $\mathrm{ONOO}^{-}$on the expression and import of premature ALAS2, transiently transfected 293 cells were treated with the chemical donors SNP and SIN-1 which generate $\mathrm{NO}$ and $\mathrm{ONOO}^{-}$respectively. Setting normoxic treatment as a control and comparing all the other treatments, including hypoxia and hypoxic cotreatments to this as shown in Figure 17, the expression and mitochondrial import of ALAS2 decreased significantly after SNP treatment under normoxic conditions whereas only mitochondrial import that was decreased significantly after SIN-1 treatment under these same conditions. Both the expression and import decreased significantly after treating transiently transfected 293 cells with hypoxia alone or hypoxia combined with either SNP or SIN-1. With hypoxia as a control for treatments that were combined with hypoxia, the expression of ALAS2 increased significantly after SNP treatment where as no significant increase was found in the mitochondrial import. SIN-1 combined with hypoxia resulted in a significant decrease in the expression of ALAS2 however no significant decrease was found in the mitochondrial import. The increase in ALAS2 expression after SNP treatment suggests a protective effect of SNP against the inhibitory additive effect of hypoxia. Comparison between all normoxic treatments as one group and all hypoxic 
treatments as another, using two-way ANOVA, revealed a significant decrease in ALAS2 total expression and mitochondrial import after treatment with hypoxia (with or without cotreatment). Combined internal group comparisons showed no significant changes. This experiment further confirms the effect of hypoxia alone, as shown by one-way ANOVA or its additive effect as shown by two-way ANOVA on ALAS2 expression and import since the results are almost the same as the previous treatments and both of them have the same degree of significance. The overall findings of this experiment are not consistent with the theory that heme binds to the leader sequence of premature ALAS2 or that NO or CO might interrupt heme binding to the leader sequence. This confirms the study by Munakata et al. (2004). The additive effect of hypoxia and $\mathrm{NO}$ or $\mathrm{ONOO}^{-}$seems to have stronger inhibitory effect on ALAS2 expression and transport even though the FLAGtagged premature ALAS2 expression was under the control of a very strong CMV promoter (Boshart et al. 1985) (Figure 17).

\subsection{Mitochondrial Isolation and ALAS2 Import}

Mitochondrial fractions were isolated from transiently transfected 293 cells to answer three important questions. The first was to determine the extent of mitochondrial transport of FLAG-tagged proteins. From the results, it was hard to differentiate between premature ALAS2 in the cytosol and premature ALAS2 imported into the mitochondria but not yet processed. The second was to provide evidence for the processing of premature ALAS2 by the MPP which occurs only in the mitochondria. The third was how ALAS2 is imported and processed under different cellular conditions. Figure 18A 
shows results that attempt to answer these questions. The results of Lanes 1 and 2 show that premature ALAS2 is imported to the mitochondria and partially processed under normal conditions as well as SNP treatment under the same conditions. Lane 3 suggests a significant decrease of both import and processing of premature ALAS2 after treating with the $\mathrm{ONOO}^{-}$generator SIN-1. Lane 4, 5, and 6 represent mitochondrial fractions of premature ALAS2 expressed under hypoxia alone or hypoxia combined with either SNP or SIN-1. These three lanes further confirm the inhibitory effect of hypoxia alone that was found in the previous two treatments (Figures 16 and 17) and also suggest the additive inhibition of hypoxia and SNP or SIN-1 in combination (Figure 17). However, some treatments from this experiment may not precisely match the results of the same treatments shown in previous experiments (Figures 16 and 17). The reasons for this might be due to protein loss from the method of protein preparation from isolated mitochondria versus the method used for whole cell extracts.

\subsection{CO and ALAS2 Expression and Mitochondrial Import}

To investigate the influence of $\mathrm{CO}$ on premature ALAS2 expression and mitochondrial import, transiently transfected 293 cells were treated with two concentrations of $\mathrm{CO}, 10 \%$ and $32 \%$, under both normoxic and hypoxic conditions. The data shown in Figure 19 demonstrated insignificant decreases in ALAS2 expression with increasing concentrations of $\mathrm{CO}$ under normoxic conditions whereas ALAS2 expression was significantly decreased under hypoxic conditions. ALAS2 import was also significantly decreased with increasing concentrations of $\mathrm{CO}$ under both normoxic and 
hypoxic conditions. Considering hypoxia as a control for hypoxic cotreatments, the expression of ALAS2 decreased significantly after $10 \%$ and $32 \%$ CO treatments. However, ALAS2 mitochondrial import increased significantly when cells were cotreated with $32 \% \mathrm{CO}$ where no significant change was found with $10 \% \mathrm{CO}$ cotreatment. Decreased amounts of tubulin, found only in combined hypoxia and $\mathrm{CO}$ exposures, suggest that these treatments may have detrimental effects on cell viability (Figure 19B; not tested for by the MTT assay). Two-way ANOVA analysis showed a significant decrease in hypoxic group of treatments combined as compared to the normoxic group of treatments, whereas no significant change was found within groups.

The data consistently show a decrease in the total FLAG-tagged ALAS2 pool under hypoxia or under hypoxia in combination with other treatments. This important observation implies that there must be a common event among all the hypoxic treatments which causes a decrease in the premature ALAS2 expression and mitochondrial import. ALAS2 is regulated at multiple levels including level of transcription, translation, and translocation into the mitochondria (Sadlon et al. 1999). Although it was previously proposed that both $\mathrm{CO}$ and NO may indirectly affect ALAS2 at the level of transcription, since they can inhibit Fe uptake transferrin (Figure 6) (Watts and Richardson, 2004), iron-dependent mechanisms of ALAS2 synthesis which also regulate its translation cannot be considered since the IRE domains were not present in the cloned ALAS2 constructs. 


\subsection{Conclusions}

Several significant and useful conclusions can be obtained from this study to promote our understanding of the role of gas molecules in ALAS2 expression and mitochondrial import under normoxic and hypoxic conditions. First, with respect to hypoxia, premature ALAS2 is regulated in non-erythroid and erythroid cells in the opposite manner. In other words, hypoxia dose not stabilize ALAS2 in non-erythroid as it does in erythroid cells. Secondly, ALAS2 feedback mechanism may not be regulated by heme or gas molecules which have high affinity to bind heme. Thirdly, $\mathrm{NO}, \mathrm{ONOO}^{-}$, and $\mathrm{CO}$ inhibit ALAS2 expression and mitochondrial import in a manner that is additive to the effects of hypoxia.

\subsection{Future Directions}

There are several directions that this study might be extended to. For instance, AbuFarha et al. (2005) illustrated that ALAS2 contains the same oxygen-dependent sequence of amino acids (LXXLAP) as HIF-1 $\underline{\alpha}$ (Figure 1). However, this sequence is not found in ALAS1 (LXXIAP) as it is in ALAS2 (Abu-Farha et al., 2005) so it might be important to mutate the isoleucine of ALAS1 to leucine and then monitor its expression and import under normoxic and hypoxic conditions in erythroid and non-erythroid cells simultaneously. Furthermore, mutated ALAS1 could be subjected to different gas molecules such as $\mathrm{O}_{2}, \mathrm{O}_{3}, \mathrm{NO}, \mathrm{ONOO}^{-}$and $\mathrm{CO}$ and also investigate how heme might regulates ALAS1 import under such treatments. It also might be useful to look at the gene 
expression of both ALAS1 and ALAS2 in both non-transfected and transfected erythroid and non-erythroid cells under different conditions in order to clearly understand the main cause of the inhibitory effect. Studying the mRNA and the protein turnover of ALAS2 may further clarify this issue. 


\section{REFERENCES}

Abu-Farha M, Niles J, and Willmore WG, 2005. Erythroid-specific 5-aminolevulinate synthase protein is stabilized by low oxygen and proteasomal inhibition. Biochem. Cell Biol. 83, 620-630.

Acuna-Castroviejo D, Escames G, Lopez LC, Hitos AB, and Leon J, 2005. Melatonin and nitric oxide: two required antagonists for mitochondrial homeostasis. Endocrine 27, 159-168.

Blaise GA, Gauvin D, Gangal M, Authier S, 2005. Nitric oxide, cell signaling and cell death. Toxicology 208, 177-192.

Boshart M, Weber F, Jahn G, Dorsch-Hasler K, Fleckenstein B, and Schaffnert W, 1985. A very strong enhancer is located upstream of an immediate early gene of human cytomegalovirus. Cell 41, 521-530.

Braun HP and Schmitz UK, 1997. The mitochondrial processing peptidase. Int. J. Biochem. Cell Biol. 29, 1043-1045.

Bunn HF and Poyton RO, 1996. Oxygen sensing and molecular adaptation to hypoxia. Physiol. Rev. 76, 839-885.

Chan MK, 2003. Mechanisms of ligand discrimination by heme proteins. J. Biol. Inorg. Chem. 8, 1-11.

Che'nais B, Molle I and Jeannesson P, 1999. Inhibitory effect of nitric oxide on chemically induced differentiation of human leukemic K562 cells. Biochem. Pharmacol. 58, 773-778. 
Dailey TA, Woodruff JH, and Dailey HA, 2005. Examination of mitochondrial protein targeting of haem synthetic enzymes: in vivo identification of three functional haem-responsive motifs in 5-aminolevulinate synthase. Biochem. J. 386, 381-386.

Erecinska M and Silver IA, 2001. Tissue oxygen tension and brain sensitivity to hypoxia. Respir. Physiol. 128, 263-276.

Furchgott RE and Zawadzki JV, 1980. The obligatory role of endothelial cells in the relaxation of arterial smooth muscle by acetylcholine. Nature $288,373-376$.

Gakh O, Cavadini P, and Isaya G, 2002. Mitochondrial processing peptidases. Biochim. Biophys. Acta. 1592, 63-77.

Goodfellow BJ, Dias JS, Ferreira GC, Henklein P, Wray V, and Macedo AL, 2001. The solution structure and heme binding of the presequence of murine 5aminolevulinate synthase. FEBS Letters 505, 325-331.

Haynes V, Elfering S, Traaseth N, and Giulivi C, 2004. Mitochondrial nitric-oxide synthase: enzyme expression, characterization, and regulation. J. Bioenerg. Biomembr. 36, 341-346.

Hervouet E, Pecina P, Demont J, Vojtiskova A, Simonnet H, Houstek J, and Godinot C, 2006. Inhibition of cytochrome $c$ oxidase subunit 4 precursor processing by the hypoxia mimic cobalt chloride. Biochem. Biophys. Res. Commun. 344, 10861093.

Hofer T, Wenger RH, Kramer MF, Ferreira GC, and Gassmann M, 2003. Hypoxic upregulation of erythroid 5-aminolevulinate synthase. Blood 101, 348-350.

Hoshi T and Lahiri S, 2004. Oxygen sensing: it's a gas. Science 306, 2050-2051. 
Huang LE and Bunn HF, 2003. Hypoxia-inducible factor and its biomedical relevance. J. Biol. Chem. 278: 19575-19578.

Huang LE, Willmore WG, Gu J, Goldberg MA, and Bunn HF, 1999. Inhibition of Hypoxia-inducible Factor 1 activation by carbon monoxide and nitric oxide implications for oxygen sensing and signaling. J. Biol. Chem. 274, 9038-9044.

Huang PL and Fishman MC, 1996. Genetic analysis of nitric oxide synthase isoforms: targeted mutation in mice. J. Mol. Med. 74, 415-421.

Ito A, 1999. Mitochondrial processing peptidase: multiple-site recognition of precursor proteins. Biochem. Biophys. Res. Commun. 265, 611-616.

Jensen RE and Kinnally KW. 1997. The mitochondrial protein import pathway: are precursors imported through membrane channels? J. Bioenerg. Biomembr. 29, 310.

Kozhukhar AV, Yasinska IM, and Sumbayev VV, 2006. Nitric oxide inhibits HIF-1 $\alpha$ protein accumulation under hypoxic conditions: implication of 2-oxoglutarate and iron. Biochimie 88, 411-418.

Kuznetsova AV, Meller J, Schnell PO, Nash JA, Ignacak ML, Sanchez Y, Conaway JW, Conaway RC, and Czyzyk-Krzeska M, 2003. Von Hippel-Lindau protein binds hyperphosphorylated large subunit of RNA polymerase II through a proline hydroxylation motif and targets it for ubiquitination. Proc. Natl. Acad. Sci. U.S.A. $100,2706-2711$.

Lathrop JT and Timko MP, 1993. Regulation by heme of mitochondrial protein transport through a conserved amino acid motif. Science $239,522-525$. 
Maines MD, 1997. The heme oxygenase system: a regulator of second messenger gases. Annu. Rev. Pharmacol. 37, 517-554.

Maneiro E, Lopez-Armanda MJ, Andress MC, Carames B, Martin MA, Hoyo P, Galado F, Arenas J, and Blanco FJ, 2005. Effect of nitric oxide on mitochondrial respiratory activity of human atricular chondrocytes. Ann. Rheum. Dis. 64, 388-395.

Mori M and Terada K, 1998. Mitochondrial protein import in animals. Biochim. Biophys. Acta. $1403,12-27$.

Morita T, Mitsialis SA, Koike H, Liu Y, and Kourembanas S, 1997. Carbon monoxide controls the proliferation of hypoxic vascular smooth muscle cells. J Biol Chem. $272,32804-32809$.

Mosmann T, 1983. Rapid colorimetric assay for cellular growth and survival: application to proliferation and cytotoxicity assays. J. Immunol. Methods. 65, 55-63.

Munakata H, Sun JY, Yoshida K, Nakatani T, Honda E, Hayakawa S, Furuyama K, and Hayashi N, 2004. Role of the heme regulatory motif in the heme-mediated inhibition of mitochondrial import of 5-aminolevulinate synthase. J. Biochem. $136,233-238$.

Nakao A, Toyokawa H, Tsung A, Nalesnik MA, Stolz DB, Kohmoto J, Ikeda A, Tomiyama K, Harada T, Takahashi T, Yang R, Fink MP, Morita K, Choi AM, Murase N, 2006. Ex vivo application of carbon monoxide in University of Wisconsin solution to prevent intestinal cold ischemia/reperfusion injury. Am. J. Transplant. 10, 2243-2255.

Ordway GA and Garry DJ, 2004. Myoglobin: an essential hemoprotein in striated muscle. J. Exp. Biol. 207, 3441-3446. 
Patel AP, Moody AJ, Handy RD, and Sneyd JR, 2003. Carbon monoxide exposure in rat heart: glutathione depletion is prevented by antioxidants. Biochem. Biophys. Res. Commun. 302, 392-396.

Patel AP, Moody AJ, Sneyd JR, and Handy RD, 2004. Carbon monoxide exposure in rat heart: evidence for two modes of toxicity. Biochem. Biophys. Res. Commun. 321, 241-246.

Pfanner N and Meijer M, 1997. Mitochondrial biogenesis: The Tom and Tim machine. Curr. Biol. 7, R100-R103.

Postovit LM, Sullivan R, Adams MA, and Graham CH, 2004. Nitric oxide signalling and cellular adaptations to changes in oxygenation. Toxicology 208, 235-248.

Rehling P, Wiedemann N, Pfanner N, and Truscott KN, 2001. The mitochondrial import machinery for preproteins. Crit. Rev. Biochem. Mol. Biol. 36, 291-336.

Ryter SW and Otterbein LE, 2004. Carbon monoxide in biology and medicine. Bioessays $26,270-280$.

Ryter SW and Tyrrell RM, 2000. The heme synthesis and degradation pathways: role in oxidant sensitivity.Heme oxygenase has both pro-and antioxidant properties. Free Radic. Biol. Med. 28, 289-309.

Sadlon TJ, Dell'Oso T, Surinya KH and May BK, Regulation of erythroid 5aminolevulinate synthase expression during erythropoiesis, 1999. Int. J. Biochem. Cell Biol. 31, 1153-1167.

Semenza, GL, 2003. Targeting HIF-1 for cancer therapy. Nat. Rev. Cancer. 3, 721-732.

Stadtman ER, 2001. Protein oxidation in aging and age-related diseases. Ann. N.Y. Acad. Sci. $928,22-38$. 
Takahashi Y, Kobayashi H, Tanaka N, Sato T, Takizawa N, and Tomita T, 1998. Nitrosyle hemoglobin in blood of normoxic and hypoxic sheep during nitric oxide inhalation. Am. Physiol. Soc. 274, H349-H357.

Tsutsui H, 2006. Mitochondrial oxidative stress and heart failure. Internal Med. 45, 809813.

Watts RN, Ponka P, and Richardson DR, 2003. Effects of nitrogen monoxide and carbon monoxide on molecular and cellular iron metabolism: mirror-image effector molecules that target iron. Biochem. J. 369, 429-440.

Watts RN and Richardson DR, 2004. Differential effects on cellular iron metabolism of the physiologically relevant diatomic effector molecules, $\mathrm{NO}$ and $\mathrm{CO}$, that bind iron. Biochim. Biophys. Acta. 1692, 1-15. 